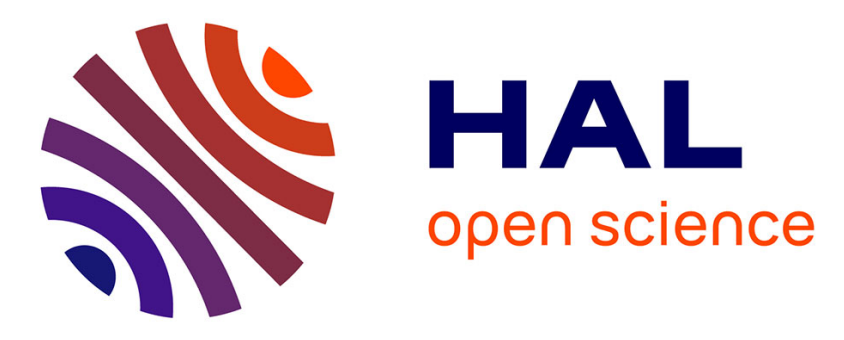

\title{
Electrochemical Oxidation and Radical Cations of Structurally Non-rigid Hypervalent Silatranes: Theoretical and Experimental Studies
}

Valery F. Sidorkin, Elena F. Belogolova, Yu Wang, Viatcheslav Jouikov, Evgeniya P. Doronina

\section{To cite this version:}

Valery F. Sidorkin, Elena F. Belogolova, Yu Wang, Viatcheslav Jouikov, Evgeniya P. Doronina. Electrochemical Oxidation and Radical Cations of Structurally Non-rigid Hypervalent Silatranes: Theoretical and Experimental Studies. Chemistry - A European Journal, 2017, 23 (8), pp.1910-1919. 10.1002/chem.201604663 . hal-01470476

HAL Id: hal-01470476

https://hal-univ-rennes1.archives-ouvertes.fr/hal-01470476

Submitted on 23 Nov 2017

HAL is a multi-disciplinary open access archive for the deposit and dissemination of scientific research documents, whether they are published or not. The documents may come from teaching and research institutions in France or abroad, or from public or private research centers.
L'archive ouverte pluridisciplinaire HAL, est destinée au dépôt et à la diffusion de documents scientifiques de niveau recherche, publiés ou non, émanant des établissements d'enseignement et de recherche français ou étrangers, des laboratoires publics ou privés. 


\section{Entry for the Table of Contents}

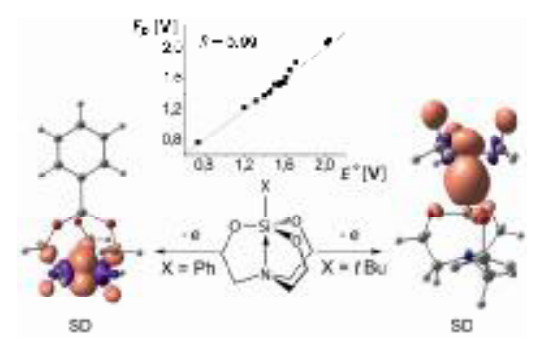

Unexpected paths of ionization of silatranes were explained within the proposed vertical model of their adiabatic ionization, providing first theoretically justified ground for the consideration of experimental peak potentials $E_{\mathrm{p}}$ versus theoretical standard oxidation potentials of hypervalent compounds of silicon. 


\title{
Electrochemical oxidation and radical cations of structurally non-rigid hypervalent silatranes. \\ Theoretical and experimental studies
}

\author{
Valery F. Sidorkin, $*{ }^{[a]}$ Elena F. Belogolova, ${ }^{[a]}$ Yu Wang, ${ }^{[b]}$ Viatcheslav Jouikov, ${ }^{[b]}$ and \\ Evgeniya P. Doronina ${ }^{[a]}$
}

[a] Prof. V. F. Sidorkin,* Dr. E. F. Belogolova, Dr. E. P. Doronina

A. E. Favorsky Irkutsk Institute of Chemistry, Siberian Branch of the Russian Academy of Sciences Favorsky, 1, Irkutsk 664033, Russian Federation

Fax: (+7)3952-419346

E-mail: $\underline{\text { svf@irioch.irk.ru }}$

[b] Prof. V. Jouikov,* Dr. Yu Wang

University of Rennes I, Molecular Chemistry and Photonics, UMR 6226 ISCR, 35042 Rennes, France E-mail: viatcheslav.jouikov@univ-rennes1.fr

Supporting information for this article is available on the WWW under http://dx.doi.org/xxxxxx. 
Abstract: Using 18 silatranes $\mathrm{XSi}\left(\mathrm{OCH}_{2} \mathrm{CH}_{2}\right)_{3} \mathrm{~N}$ (1) as an example, the potentials of electrochemical oxidation $E^{0}$ of the hypervalent compounds of $\mathrm{Si}$ were calculated for the first time at the $a b$ initio and DFT levels. The experimental peak potentials $E_{\mathrm{p}}$ show an excellent agreement $(M A E=0.03)$ with the MP2//B3PW91 calculated $E^{0}(\mathrm{C}-\mathrm{PCM})$. Radical cations of 1 reveal a "stretch isomerism" of the $\mathrm{N} \rightarrow \mathrm{Si}$ dative bond. Localization of the spin density (SD) on the substituent $\mathrm{X}$ and the short $(s)$ coordination contact $\mathrm{Si}^{\cdots} \mathrm{N}\left(\mathrm{d}_{\mathrm{SiN}}<2.13 \AA\right)$ along with the high pentacoordinate character of Si are typical for the first isomer $\mathbf{1}^{+\bullet(s)}$, whereas the second one, $\mathbf{1}^{+\bullet(l)}$, has a longer $(l) \mathrm{Si}^{\cdots} \mathrm{N}$ distance $\left(\mathrm{d}_{\mathrm{SiN}}>3.0 \AA\right)$, the tetra-coordinated $\mathrm{Si}$ and the $\mathrm{SD}$ localized on the silatrane nitrogen atom $\mathrm{N}_{\mathrm{s}}$. The vertical model of adiabatic ionization $\left(\mathbf{1} \rightarrow \mathbf{1}^{+\bullet(\mathrm{s})}\right.$ or $\left.\mathbf{1} \rightarrow \mathbf{1}^{+\bullet(\mathrm{l})}\right)$ was developed. It allows, in accordance with an original experimental test (electrooxidation of $\mathbf{1}$ in the presence of ferrocene), reliably predicting the most probable pathways of the silatrane oxidation. The reliable relationships of $E^{0}(\mathbf{1})$ with the strength characteristics of the dative contact $\mathrm{N} \rightarrow \mathrm{Si}$ were revealed.

Keywords: Hypervalent compounds, Group 14 elements, Cyclic voltammetry, Oxidation, ab initio and DFT calculations 


\section{Introduction}

Electrochemical oxidation of hypervalent metallatranes $\mathrm{XM}\left(\mathrm{OCH}_{2} \mathrm{CH}_{2}\right)_{3} \mathrm{~N}$ (I, with $\mathrm{M}=\mathrm{Si}$, $\mathrm{Ge}, \mathrm{Sn} . .$. ) has been shown to produce radical cations (RCs) possessing a unique structure and having a great promise for the potential applications. ${ }^{[1-7]}$ To cite a few, these might be a new type of molecular wires, spin switches and electromechanical systems. ${ }^{[4 c, 5]}$ Their potential in surface research has been demonstrated for corrosion protection of metals ${ }^{[7]}$ and functional capping of carbonaceous interfaces. ${ }^{[1]}$

This raising interest to the redox chemistry of metallatranes is impeded by a substantial gap between the levels of experimental and theoretical works in this field. Remarkably, up to date there were even no attempts to calculate the redox potentials of intramolecular complexes of the group 14 elements, including metallatranes, that are anomalously sensitive to the media (solvent) effects. ${ }^{[8-11]}$ Meanwhile, a good agreement of the calculated and experimental oxidation potentials would guarantee the correct understanding of the role of the substituent at the atrane $\mathrm{M}$ atom in the ability of such systems to release an electron and in the response of their spatial and orbital structure to this process.

Here we focus on the study of electrochemical oxidation of silatranes $\mathrm{XSi}\left(\mathrm{OCH}_{2} \mathrm{CH}_{2}\right)_{3} \mathrm{~N}(\mathbf{1})$ that are key objects in the chemistry of organic derivatives of the penta-coordinated silicon $\left(\mathrm{Si}^{\mathrm{V}}\right)$ and that have been earlier studied by a large variety of physico-chemical methods. ${ }^{[8,11 a, 12]}$ The removal of electron from $\mathbf{I}$, and in particular from $\mathbf{1}$, may affect either the atrane nitrogen atom or the substituent X. Obviously, this renders the whole identification of their primary radical cations quite complex. ${ }^{[3-6]}$ Note that for a number of compounds of the $\mathrm{XSi}\left(\mathrm{OCH}_{2} \mathrm{CH}_{2}\right)_{3} \mathrm{~N}$ family, e.g. for 1halogen substituted $(\mathrm{X}=\mathrm{Cl}, \mathrm{Br})$ derivatives with the shortest dative contacts $\mathrm{N} \rightarrow \mathrm{Si}$, the oxidation potentials are not available and it is even not clear if they are oxidizable at al. ${ }^{[3,13]}$

The present contribution therefore aims: 1) the experimental and theoretical study of the electrochemical oxidation of 1-X-substituted silatranes $\mathrm{XSi}\left(\mathrm{OCH}_{2} \mathrm{CH}_{2}\right)_{3} \mathrm{~N}$ (Scheme 1), 2) assessing the nature of their radical cations - primary products of the electron withdrawal, - and 3) revealing the trends in the change of $E^{0}(\mathbf{1})$ under the influence of geometrical, electronic, energetic and orbital characteristics of the $\mathrm{N} \rightarrow \mathrm{Si}$ coordination.

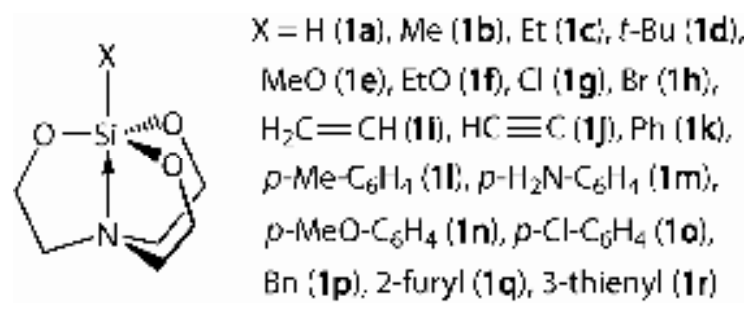

Scheme 1. The silatranes studied. 


\section{Results and Discussion}

Structure of the $\mathbf{N} \rightarrow \mathrm{Si}$ coordination bond "stretch isomers" of the silatrane radical cations

The neutral silatranes 1a-1r with a penta-coordinated Si atom (see $\eta_{e}$ in Table $S 1$ in the Supporting Information) have only one minimum on the potential energy surface (PES), in accordance with the literature data. ${ }^{[8,10,13,14]}$ On the contrary, their RCs show a "stretch isomerism" of the $\mathrm{N} \rightarrow \mathrm{Si}$ dative bond. $^{[16]}$ Indeed, two minima were found on the B3PW91 and MP2 PES of $\mathbf{1 a}^{+\bullet}-\mathbf{1} \mathbf{r}^{+\bullet}$ (see Table 1 and the examples on Figure 1).

Table 1. B3PW91/6-311G(d,p) and MP2/6-311G(2d,p) (bold) calculated (C-PCM, acetonitrile) interatomic distances $\mathrm{SiN}\left(d_{\mathrm{SiN}}[\AA]\right)$ and $\mathrm{XSi}\left(d_{\mathrm{XSi}}[\AA]\right)$ in silatranes $\mathrm{XSi}\left(\mathrm{OCH}_{2} \mathrm{CH}_{2}\right)_{3} \mathrm{~N}(\mathbf{1})$ and their RCs $\left(\mathbf{1}^{+\bullet}\right)$, relative stability of "isomers" $\mathbf{1}^{+\bullet(l)}$ and $\mathbf{1}^{+\bullet(s)}\left(\Delta G_{s-l},{ }^{[a]}\left[\mathrm{kcal} \mathrm{mol}^{-1}\right]\right)$.

\begin{tabular}{|c|c|c|c|c|c|c|c|}
\hline \multirow[t]{2}{*}{$X$} & \multicolumn{3}{|c|}{$d_{\mathrm{SiN}}$} & \multicolumn{3}{|c|}{$d_{\mathrm{SiX}}$} & \multirow[t]{2}{*}{$\Delta G_{s-l}$} \\
\hline & 1 & $\mathbf{1}^{+\bullet(l)}$ & $\mathbf{1}^{+\bullet(s)}$ & 1 & $\mathbf{1}^{+\bullet(l)}$ & $\mathbf{1}^{+\bullet(s)}$ & \\
\hline \multirow[t]{2}{*}{$\mathrm{H}$} & 2.167 & 3.084 & 1.900 & 1.491 & 1.462 & 1.866 & $13.97 / 13.06$ \\
\hline & 2.132 & 3.043 & 1.856 & 1.485 & 1.453 & 2.467 & 10.13 \\
\hline \multirow[t]{2}{*}{$\mathrm{Me}$} & 2.267 & 3.116 & 1.928 & 1.878 & 1.833 & 2.338 & $9.17 / 8.99$ \\
\hline & 2.188 & 3.069 & 1.902 & 1.882 & 1.834 & 2.401 & 9.40 \\
\hline \multirow[t]{2}{*}{ Et } & 2.278 & 3.117 & 1.944 & 1.885 & 1.843 & 2.303 & $2.25 /-$ \\
\hline & 2.192 & 3.065 & 1.916 & 1.885 & 1.839 & 2.338 & 2.22 \\
\hline \multirow[t]{2}{*}{$t \mathrm{Bu}$} & 2.310 & 3.117 & 1.961 & 1.910 & 1.866 & 2.392 & $-4.97 /-5.07$ \\
\hline & 2.208 & 3.060 & 1.936 & 1.904 & 1.852 & 2.367 & -5.59 \\
\hline \multirow[t]{2}{*}{$\mathrm{MeO}$} & 2.188 & 3.076 & 1.968 & 1.677 & 1.613 & 1.867 & $22.51 /-$ \\
\hline & 2.156 & 3.035 & 1.939 & 1.676 & 1.613 & 1.913 & 22.35 \\
\hline \multirow[t]{2}{*}{$\mathrm{EtO}$} & 2.190 & 3.079 & 1.976 & 1.677 & 1.614 & 1.852 & $22.92 / 22.66$ \\
\hline & 2.156 & 3.037 & 1.944 & 1.677 & 1.614 & 1.902 & 22.08 \\
\hline \multirow[t]{2}{*}{$\mathrm{Cl}$} & 2.092 & 3.044 & 2.068 & 2.158 & 2.024 & 2.096 & $50.73 / 49.24$ \\
\hline & 2.059 & 3.007 & 1.890 & 2.174 & 2.032 & 2.575 & 27.18 \\
\hline \multirow[t]{2}{*}{$\mathrm{Br}$} & 2.086 & 3.054 & 1.947 & 2.338 & 2.186 & 2.455 & $14.48 /-$ \\
\hline & 2.043 & 3.010 & 1.895 & 2.366 & 2.205 & 2.726 & 9.73 \\
\hline \multirow[t]{2}{*}{$\mathrm{H}_{2} \mathrm{C}=\mathrm{CH}$} & 2.232 & 3.106 & 2.016 & 1.881 & 1.832 & 2.001 & $16.29 / 15.41$ \\
\hline & 2.168 & 3.058 & 1.993 & 1.884 & 1.831 & 2.003 & 15.17 \\
\hline \multirow[t]{2}{*}{$\mathrm{HC} \equiv \mathrm{C}$} & 2.159 & 3.073 & 2.091 & 1.869 & 1.798 & 1.851 & $37.22 /-$ \\
\hline & 2.110 & 3.032 & $-[b]$ & 1.875 & 1.803 & $-[b]$ & - \\
\hline $\mathrm{Ph}$ & 2.235 & 3.103 & 2.062 & 1.896 & 1.840 & 1.961 & $16.61^{[c]} / 15.98^{[c]}$ \\
\hline
\end{tabular}




\begin{tabular}{|c|c|c|c|c|c|c|c|}
\hline & 2.158 & 3.054 & $-[b]$ & 1.894 & 1.836 & $-[b]$ & - \\
\hline \multirow[t]{2}{*}{$p-\mathrm{Me}-\mathrm{C}_{6} \mathrm{H}_{4}$} & 2.243 & 3.107 & 2.088 & 1.893 & 1.836 & 1.932 & $8.95^{[c]} /-$ \\
\hline & 2.162 & 3.057 & $-[b]$ & 1.893 & 1.834 & $-[b]$ & - \\
\hline \multirow[t]{2}{*}{$p-\mathrm{H}_{2} \mathrm{~N}-\mathrm{C}_{6} \mathrm{H}_{4}$} & 2.267 & 3.120 & 2.127 & 1.885 & 1.826 & 1.920 & $-15.12^{[c]} /-13.66^{[c]}$ \\
\hline & 2.174 & 3.065 & 2.047 & 1.888 & 1.828 & 1.932 & $\mathbf{- 1 0 . 4 4} 4^{[c]}$ \\
\hline \multirow[t]{2}{*}{$p-\mathrm{MeO}-\mathrm{C}_{6} \mathrm{H}_{4}$} & 2.249 & 3.113 & 2.107 & 1.890 & 1.832 & 1.926 & $-0.58^{[c]} /-0.27^{[c]}$ \\
\hline & 2.164 & 3.059 & 2.025 & 1.890 & 1.831 & 1.941 & $\mathbf{3 . 7 7 ^ { [ c ] }}$ \\
\hline \multirow[t]{2}{*}{$p-\mathrm{Cl}-\mathrm{C}_{6} \mathrm{H}_{4}$} & 2.215 & 3.096 & 2.083 & 1.899 & 1.841 & 1.933 & $15.28^{[c]} /-$ \\
\hline & 2.143 & 3.048 & $-[b]$ & 1.897 & 1.838 & $-[b]$ & - \\
\hline \multirow[t]{2}{*}{$\mathrm{PhCH}_{2}$} & 2.235 & 3.106 & 2.024 & 1.901 & 1.852 & 2.101 & $-3.66^{[c]} /-3.66^{[c]}$ \\
\hline & 2.161 & 3.054 & 2.017 & 1.900 & 1.846 & 2.044 & $\mathbf{2 . 3 4} 4^{[c]}$ \\
\hline \multirow[t]{2}{*}{ 2-furyl } & 2.185 & 3.085 & 2.046 & 1.888 & 1.828 & 1.940 & $-4.81 /-$ \\
\hline & 2.123 & 3.038 & 2.015 & 1.886 & 1.828 & 1.936 & -3.54 \\
\hline \multirow[t]{2}{*}{ 3-thienyl } & 2.218 & 3.101 & $(2.083)$ & 1.888 & 1.829 & (1.924) & $(20.29)^{[c]}-/$ - \\
\hline & 2.146 & 3.053 & 2.059 & 1.886 & 1.826 & 1.914 & $1.93^{[c]}$ \\
\hline
\end{tabular}

[a] The calculation of $\Delta G_{s-l}$ was carried out at the MP2/6-311G(2d,p)//B3PW91/6-311G(d,p), MP2/6311++G(3df,3pd)//B3PW91/6-311G(d,p) (italics) and MP2/6-311G(2d,p)//MP2/6-311G(2d,p) (bold) levels of theory. In parenthesis, the B3PW91 values are given for the transition structure $\mathbf{1} \mathbf{r}^{+\bullet(s)}$ having one small negative force constant. The positive sign of $\Delta G_{s-l}$ means preference for $\mathbf{1}^{+\bullet(l)}$ with a long SiN contact. [b] Convergence problems during the geometry optimization of $\mathbf{1}^{+\bullet(s)}$. [c] $\Delta G_{s-l}$ were estimated using the spin projection procedure. For all RCs $\mathbf{1}^{+\bullet(l)}$ and also for the species $\mathbf{1}^{+\bullet(s)}$ formed from silatranes $\mathrm{XSi}\left(\mathrm{OCH}_{2} \mathrm{CH}_{2}\right)_{3} \mathrm{~N}$ whose substituent $\mathrm{X}$ does not contain multiple bonds, the $\left\langle S^{2}\right\rangle$ value makes up $0.75-0.77$ for the UMP2 wave function. In the case of $\mathbf{1}^{+\bullet(s)}$ with $\mathrm{X}=\mathrm{CH}_{2}=\mathrm{CH}, \mathrm{HC} \equiv \mathrm{C}, p$-Me$\mathrm{C}_{6} \mathrm{H}_{4}$, and 2-furyl, the $\left\langle S^{2}\right\rangle$ value is still within the predetermined ${ }^{[15]}$ threshold of $0.75-0.82$. Removing the highlaying spin states from the UMP2 functions of $\mathbf{1}^{+\bullet(s)}$ with $\mathrm{X}=\mathrm{Ph}, p$-ClPh, 3-thienyl and $p$-MeO-Ph $\left(\left\langle S^{2}\right\rangle^{\mathrm{UMP} 2} \sim 0.89-\right.$ $0.99)$ through applying the spin-projection operator yields acceptable $\left\langle S^{2}\right\rangle$ values $\left(\left\langle S^{2}\right\rangle^{\mathrm{PMP} 2} \sim 0.76-0.79\right)$. Only for two species $\mathbf{1}^{\bullet(s)}$ - with $\mathrm{X}=p-\mathrm{NH}_{2} \mathrm{Ph}$ and $\mathrm{Ph}-\mathrm{CH}_{2}\left(\left\langle S^{2}\right\rangle^{\mathrm{UMP} 2} \sim 1.15-1.18\right)-$ the $\left\langle S^{2}\right\rangle$ value remains high even after spin-projection $\left(\left\langle S^{2}\right\rangle^{\mathrm{PMP} 2} \sim 0.88-0.89\right)$.

The first minimum corresponds to the "isomers" $\mathbf{1}^{+\bullet(s)}$ with a relatively short $\mathrm{N} \rightarrow \mathrm{Si}$ coordination contact $\left(d_{\mathrm{SiN}}<2.13 \AA\right)$, while the second one to the "isomers" $\mathbf{1}^{+\bullet(l)}$ with a long $d_{\mathrm{SiN}}(>$ $3.0 \AA)$. 


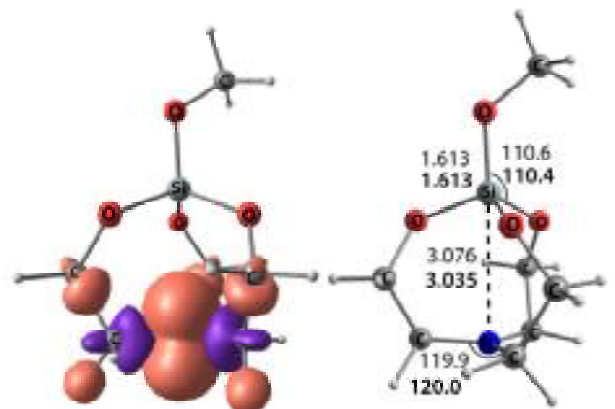

$\operatorname{SD} 1 e^{+(n)}$

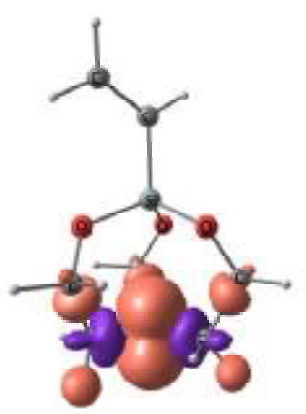

SD $1 i^{+* 16}$
$1 e^{++\infty}$

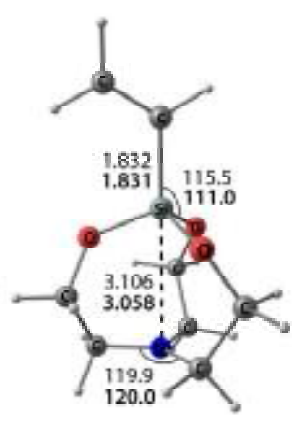

$1 i^{+*(\pi)}$

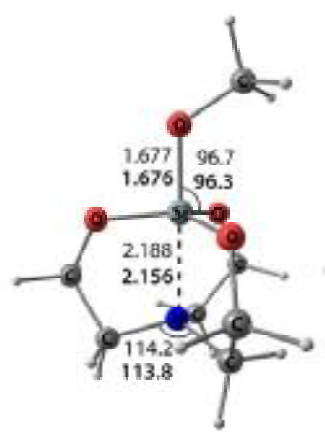

10

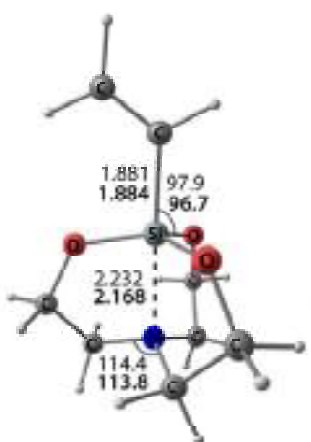

$1 i$

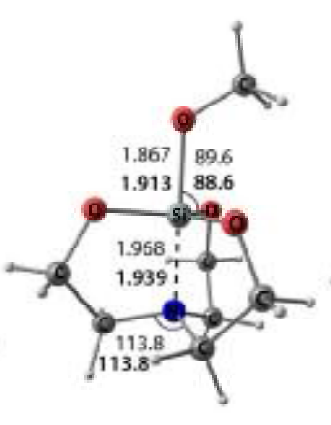

$1 e^{+|s\rangle}$

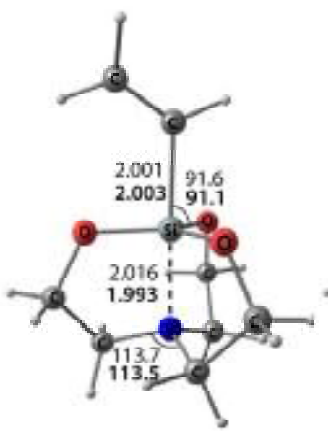

$11^{+*(s)}$

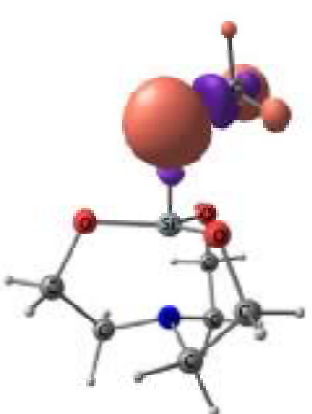

$\operatorname{SD} 1 e^{+\cdot|s\rangle}$

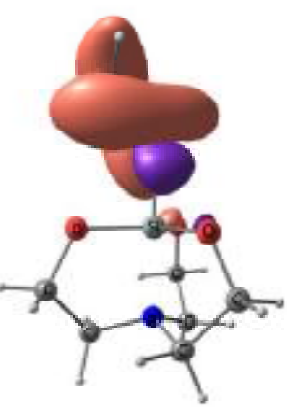

SD $1 \mathbf{i}^{+* \mid 3\}}$

Figure 1. B3PW91/6-311G(d,p) and MP2/6-311G(2d,p) (bold) geometries of methoxysilatrane (1e) and vinylsilatrane (1i), of their RCs $1 \mathbf{e}^{+\bullet(l)}, \mathbf{1 e}^{+\bullet(s)}, \mathbf{1 i}^{\mathbf{+}^{\bullet}(l)}, \mathbf{1 i}^{\mathbf{+}^{\bullet}(s)}$, as well as UMP2/6-311G(2d,p) spin density distribution in the RCs at 0.004 au contour level in acetonitrile solution.

The "stretch isomerism" in $\mathbf{1}^{+\bullet}$ arises from the presence of two probable sites of electron withdrawal in the $\mathrm{N} \rightarrow \operatorname{SiX} 3 \mathrm{c}-4 \mathrm{e}$ axial system of 1 : silatrane nitrogen atom $\mathrm{N}_{\mathrm{s}}$ and the substituent $\mathrm{X}$ ( $\mathrm{Si}-\mathrm{X}$ bond). If after the electron detachment the unpaired electron is mostly localized on $\mathrm{N}_{\mathrm{s}}$ (depletion of electron density at this center), a $\mathbf{1}^{+\bullet(l)} \mathrm{RC}$ is formed, otherwise it would be $\mathbf{1}^{+\bullet(s)}$ with $\mathrm{SD}$ mainly residing on the $\mathrm{X}$ substituent (see examples in Figure 1). For this reason, the coordination (donor) ability of $\mathrm{N}_{\mathrm{s}}$ is reduced in $\mathbf{1}^{+\bullet(l)}$ whereas in $\mathbf{1}^{+\bullet(s)}$ the $\sigma$-acceptor properties of Si towards $\mathrm{N}_{\mathrm{s}}$ are overall increased compared with those in the parent neutral molecules. It is to underline that qualitatively, the character of SD distribution in $\mathbf{1}^{\mathbf{+}}$ is independent on the choice of the wave function (UB3PW91/6-311G(d,p) or UMP2/6-311G(2d,p)) (see Figure S1).

The transition from $\mathbf{1}$ to $\mathbf{1}^{+\bullet(l)}$ is accompanied by not only a dramatic weakening of the $\mathrm{N} \rightarrow \mathrm{Si}$ interaction, i.e. by increasing the internuclear $\mathrm{Si} \cdots \mathrm{N}$ distance by more than $0.8 \AA$ (!) (Table 1 , Figure 1), but also by shortening the axial $\mathrm{Si}-\mathrm{X}$ and equatorial Si-O bonds (Table 1, Table S1). The $\mathrm{N}_{\mathrm{s}}$ atom is now practically flat (see the $\angle \mathrm{CNC}$ angle values in Figure 1 and $\Delta_{\mathrm{N}}$ in Table $\mathrm{S} 1$ in the Supporting Information), the Supporting Information while the silicon atom becomes tetracoordinated, $\eta_{e}=0$. On the contrary, and according to the above said, the dative contacts $\mathrm{N} \rightarrow \mathrm{Si}$ in 
$\mathbf{1}^{+\bullet(s)}$ become shorter with respect to those in neutral $\mathbf{1}$ while the SiX bonds become longer (Table 1 and Table S1). Consequently, the penta-coordinate character, $\eta_{e}$, of the silicon atom and the tetrahedrality, $\Delta_{\mathrm{N}}$, of the atrane nitrogen generally increase upon the $\mathbf{1} \rightarrow \mathbf{1}^{+\bullet(s)}$ ionization (Table S1).

The geometry optimization method has only small impact on the above featured trends in the structural changes in $\mathbf{1}$ induced by electron withdrawal. The largest discrepancy in the MP2 and B3PW91 calculated structural parameters of $\mathbf{1}$ and $\mathbf{1}^{+\bullet}$ is observed for the interatomic SiN and SiX distances (Tables 1 and S1): $d_{\mathrm{SiN}}, d_{\mathrm{XSi}}$ (B3PW91) are 0.03-0.10 $\AA$ longer than $d_{\mathrm{SiN}}$ and $d_{\mathrm{XSi}}$ from MP2. Only for $\mathbf{1 \mathbf { a } ^ { + \bullet ( s ) }}, \mathbf{1 g}^{+\bullet(s)}$ and $\mathbf{1 h}^{+\bullet(s)}$ the difference in $d_{\mathrm{XSi}}$ is beyond this interval. In this respect it is appropriate to recall that according to the data available on the neutral hypervalent molecules of silatranes, ${ }^{[9,17]}$ both the MP2 and B3PW91 methods have problems in describing the Si-Hal bond length; besides, the MP2 method usually overestimates the dative $\mathrm{N} \rightarrow \mathrm{Si}$ bonding compared to DFT (see ${ }^{[9]}$ and Refs therein).

\section{Relative stability of the radical cation states of silatranes}

The values $\Delta G_{s-l}$ for 16 out of 18 considered silatranes (Table 1), obtained by the UMP2 method with the 6-311G(2d,p) and 6-311++G(3df,3pd) basis sets for the UB3PW91 and UMP2 $2^{[17]}$ geometries are in a good quantitative (qualitative for the $\mathrm{RC}$ of $\mathrm{Cl}$-silatrane) agreement.

For benzyl- (1p) and p-MeO- $\mathrm{C}_{6} \mathrm{H}_{4}$-silatranes (1n), the sign of $\Delta G_{s-l}$ (i.e. the relative stability of their $\mathbf{1}^{+\bullet(s)}$ and $\mathbf{1}^{+\bullet(l)}$ isomers) turned out to be dependent on whether the MP2//B3PW91 or MP2//MP2 level of theory was used (Table 1). The positive $\Delta G_{s-l}$ for the MP2 geometries suggests the existence of RCs of $\mathbf{1 p}$ and $\mathbf{1 n}$ exclusively in the $\mathbf{1}^{\mathbf{+}(l)}$ form. In contrast, B3PW91 describes $\mathbf{1} \mathbf{p}^{+\bullet(s)}$ to be the preferred isomer while $1 \mathbf{n}^{+\bullet}$ must exist in equilibrium $1 \mathbf{n}^{\bullet(s)} \leftrightarrow \mathbf{1 n}^{\bullet(l)}$.

The HOMOs in both $\mathbf{1 p}$ and $\mathbf{1 n}$ are mostly localized on their aromatic $\pi$-systems and are more than $0.5 \mathrm{eV}$ higher in energy than that in Ph-silatrane 1k (Table S2). The NBO analysis suggests the reason of this to be the intensive (> $\left.12 \mathrm{kcal} \mathrm{mol}^{-1}\right) 4 \mathrm{e}$ exchange repulsion between the aromatic $\pi$-orbitals and the oxygen lone electron pair (LEP) in $\mathbf{1 n}$ (or the $\sigma(\mathrm{Si}-\mathrm{C})$ bond in $\mathbf{1 p}$ ), which is absent in $\mathbf{1 k}$, as well as in the other aryl silatranes $\mathbf{1 1}, \mathbf{1} \mathbf{m}$, and $\mathbf{1 0}$. This is perfectly in line with the remarkably easier oxidation of benzyl silatrane compared to phenyl silatrane (see Table 3 in the next Section); similar trend holds for oxidation of benzyl and phenyl silanes in general. ${ }^{[19]}$

As mentioned above (Table 1 , footnote $[c]$ ), the estimated difference $\Delta G_{s-l}$ for $\mathbf{1 p}^{+\bullet}$ was not quite correct because the $\left\langle S^{2}\right\rangle$ value for the UMP2 function of $\mathbf{1} \mathbf{p}^{+\bullet(s)}$ remains too high even after applying the projection procedure. It was therefore interesting to consider $\Delta G_{s-l}$ at the ROMP2/6$311 \mathrm{G}(2 \mathrm{~d}, \mathrm{p})$ level of theory. Unfortunately, the minimum for the $\mathbf{1} \mathbf{p}^{+\bullet(l)}$ isomer on PES of $\mathbf{1 p}^{\mathbf{+} \boldsymbol{}}$ could 
not be localized. With this, both the expected RCs, $\mathbf{1 b}^{+\bullet(s)}$ and $\mathbf{1} \mathbf{b}^{+\bullet(l)}$, were found using the ROPM2 method for methyl silatrane $\mathbf{1 b}$ and the data on their geometry and relative stability were in perfect agreement with the UMP2 calculations $\left(\Delta G_{s-l}=9.40\right.$ (UMP2) and $\left.9.53(\mathrm{ROMP} 2) \mathrm{kcal} \mathrm{mol}^{-1}\right)$. Note that the problems of treating the open shell systems within the restricted MP2 method (ROPM2) are known. ${ }^{[19]}$

Considering $\mathbf{1} \mathbf{b}^{+\bullet}$ and $\mathbf{1} \mathbf{p}^{+\bullet}$, we found out that the choice of the polarized continuum model (C-PCM, COSMO, IEF-PCM, and SMD) is not crucial for assessing $\Delta G_{s-l}$ of the isomer forms of $\mathbf{1}^{+\bullet}$ (See Table S3). Nonetheless, the SMD calculation scheme - compared to others underestimates the effect of the non-specific solvation on the oxidation potential (see vide infra).

Is it possible, knowing the type of HOMO (amplitudes magnitude) in neutral $\mathbf{1}$, to predict the most probable way of its adiabatic ionization $\left(\mathbf{1} \rightarrow \mathbf{1}^{+\bullet(s)}\right.$ or $\left.\mathbf{1} \rightarrow \mathbf{1}^{+\bullet(l)}\right)$ ? Because of the extreme sensitivity of the silatranes geometry to the oxidation process (see the next Section), the answer is in general case negative. Yet this problem can be resolved within the vertical model of adiabatic ionization, $\mathbf{1}^{\mathrm{n} \text {-eq } / / \mathbf{1}^{+\bullet(s)}} \rightarrow \mathbf{1}^{+\bullet(s)}$ or $\mathbf{1}^{\mathrm{n} \text {-eq } / / \mathbf{1}^{+\bullet(l)}} \rightarrow \mathbf{1}^{+\bullet(l)}$, i.e. when considering HOMOs of the nonequilibrium structures of neutral silatranes $\mathbf{1}^{\text {n-eq }}$ with the geometries of the corresponding RCs, $\mathbf{1}^{+\bullet(s)}$ or $\mathbf{1}^{+\bullet(l)}$.

From both the MP2//B3PW91 and MP2//MP2 calculations, only for three (1d, $1 \mathbf{m}$ and 1q) out of 16 silatranes $\mathrm{XSi}\left(\mathrm{OCH}_{2} \mathrm{CH}_{2}\right)_{3} \mathrm{~N}$ the localization of SD in the corresponding RCs is preferred on $\mathrm{X}$ (on the $\mathrm{Si}-\mathrm{X}$ bond in $\mathbf{1 d}$ ) and not on $\mathrm{N}_{\mathrm{s}}$. For other 13 silatranes, a "proper" oxidation pathway is inherent: electron is removed form $\mathrm{N}_{\mathrm{s}}$ and the corresponding RCs are exclusively formed in the $\mathbf{1}^{+\bullet}(l)$ configuration (Table 1). For 8 molecules $(\mathbf{1 a - 1 c}, \mathbf{1 e - 1 g}, \mathbf{1 i}$ and $\mathbf{1 j})$ in this latter group, the type of HOMO $\left(\mathrm{n}_{\mathrm{Ns}}\right)$ in the equilibrium $\mathbf{1}^{+\bullet(l)}$ and non-equilibrium $\mathbf{1}^{\mathrm{n} \text {-eq }} / / \mathbf{1}^{\bullet \bullet(l)}$ structures is the same (see, for instance, 1a and 1i, Table 2). Only in this case, the HOMO character gives a reliable hint as to the most likely way of the adiabatic ionization of silatranes.

In contrast, the HOMOs of the remaining five compounds $(\mathbf{1 h}, \mathbf{1 k}, \mathbf{1 l}, \mathbf{1 0}$ and $\mathbf{1 r})$ are mainly localized on the substituent X (Figure 2, Table S2) that does not allow to explain the observed "proper" oxidation of these silatranes. Once again, this becomes possible when considering the HOMOs of the corresponding non-equilibrium structures $\mathbf{1}^{\mathrm{n}-\mathrm{eq}} / \mathbf{1}^{+\bullet(l)}$ demonstrating the "correct" localization of HOMO on $\mathrm{N}_{\mathrm{s}}$ (e.g. 1k, Table 2).

Table 2. HOMO and its OVGF/6-311G(d,p) energy $\left(\varepsilon_{i}[\mathrm{eV}]\right)$ for several silatranes $\mathrm{XSi}\left(\mathrm{OCH}_{2} \mathrm{CH}_{2}\right)_{3} \mathrm{~N}$ with the equilibrium (1) and non-equilibrium $\left(\mathbf{1}^{\mathrm{n}-\mathrm{eq}} / / \mathbf{1}^{+\bullet}\right)$ geometries ${ }^{[a]}$ corresponding to the RCs $\mathbf{1}^{+\bullet(s)}$ and $\mathbf{1}^{+\bullet(l)}$. 


\begin{tabular}{|c|c|c|c|}
\hline \multirow[t]{2}{*}{$\mathrm{X}$} & \multirow[t]{2}{*}{ species } & \multicolumn{2}{|c|}{ HOMO } \\
\hline & & type & $-\varepsilon_{i}$ \\
\hline \multirow[t]{3}{*}{$\mathrm{H}$} & $1 \mathbf{a}^{\mathrm{n}-\mathrm{eq}} / / \mathbf{1} \mathrm{a}^{+\bullet(s)}$ & $\sigma_{\mathrm{SiH}}$ & 8.63 \\
\hline & $1 \mathbf{a}$ & $\mathrm{n}_{\mathrm{Ns}}$ & 9.99 \\
\hline & $\mathbf{1} \mathbf{a}^{\mathrm{n}-\mathrm{eq}} / / \mathbf{1} \mathbf{a}^{+\bullet(l)}$ & $\mathrm{n}_{\mathrm{Ns}}$ & 7.44 \\
\hline \multirow[t]{3}{*}{$t-\mathrm{Bu}$} & $\mathbf{1 d}^{\mathrm{n}-\mathrm{eq}} / / \mathbf{1} \mathbf{d}^{+\bullet(s)}$ & $\sigma_{\mathrm{SiC}}$ & 5.91 \\
\hline & 1d & $\sigma_{\mathrm{SiC}}$ & 9.01 \\
\hline & $\mathbf{1} \mathbf{d}^{\mathrm{n}-\mathrm{eq}} / / \mathbf{1} \mathbf{d}^{+\bullet(l)}$ & $\mathrm{n}_{\mathrm{Ns}}$ & 7.31 \\
\hline \multirow[t]{3}{*}{$\mathrm{H}_{2} \mathrm{C}=\mathrm{CH}$} & $\mathbf{1} \mathbf{i}^{\mathrm{n}-\mathrm{eq}} / / \mathbf{1} \mathbf{i}^{+\bullet(s)}$ & $\pi_{\mathrm{X}}$ & 7.95 \\
\hline & $1 \mathbf{i}$ & $\mathrm{n}_{\mathrm{Ns}}$ & 9.61 \\
\hline & $\mathbf{1} \mathbf{i}^{\mathrm{n}-\mathrm{eq}} / / \mathbf{1} \mathbf{i}^{+\bullet(l)}$ & $\mathrm{n}_{\mathrm{Ns}}$ & 7.37 \\
\hline \multirow[t]{3}{*}{$\mathrm{Ph}$} & $\mathbf{1} \mathbf{k}^{\mathrm{n}-\mathrm{eq}} / / \mathbf{1} \mathbf{k}^{+\bullet(s)}$ & $\pi_{\mathrm{Ph}}$ & 8.06 \\
\hline & $1 \mathbf{k}$ & $\pi_{\mathrm{Ph}}$ & 8.77 \\
\hline & $\mathbf{1} \mathbf{k}^{\mathrm{n}-\mathrm{eq}} / / \mathbf{1} \mathbf{k}^{+\bullet(l)}$ & $\mathrm{n}_{\mathrm{Ns}}$ & 7.35 \\
\hline \multirow[t]{6}{*}{$p-\mathrm{MeO}-\mathrm{C}_{6} \mathrm{H}_{4}$} & $\mathbf{1} n^{\mathrm{n}-\mathrm{eq}} / / \mathbf{1 n}^{+\bullet(s)}$ & $\pi_{\mathrm{X}}$ & 7.32 \\
\hline & & & 7.28 \\
\hline & 1n & $\pi_{\mathrm{X}}$ & 7.90 \\
\hline & & & 7.85 \\
\hline & $\mathbf{1} \mathbf{n}^{\mathrm{n}-\mathrm{eq}} / / \mathbf{1}^{+\bullet(l)}$ & $\mathrm{n}_{\mathrm{Ns}}$ & 7.32 \\
\hline & & & 7.34 \\
\hline \multirow[t]{6}{*}{$\mathrm{PhCH}_{2}$} & $\mathbf{1} \mathbf{p}^{\mathrm{n}-\mathrm{eq}} / / \mathbf{1} \mathbf{p}^{+\bullet(s)}$ & $\pi_{\mathrm{X}}$ & 6.90 \\
\hline & & & 6.99 \\
\hline & $1 p$ & $\pi_{\mathrm{X}}$ & 8.21 \\
\hline & & & 7.99 \\
\hline & $\mathbf{1} \mathbf{p}^{\mathrm{n}-\mathrm{eq}} / / \mathbf{1} \mathbf{p}^{+\bullet(l)}$ & $\mathrm{n}_{\mathrm{Ns}}$ & 7.57 \\
\hline & & & 7.78 \\
\hline
\end{tabular}

[a] The geometry optimization was performed at the UB3PW91/6-311G(d,p) and UMP2/6-311G(2d,p) (bold) levels of theory in acetonitrile (C-PCM).

Now, why the transition from $\mathbf{1}$ to $\mathbf{1}^{\text {n-eq }}$ (for instance, upon varying $d_{\mathrm{SiN}}$ in $\mathbf{1}$ ) in some cases involves the inversion of MO levels while in the others it does not? Figure 2 explains it in a visual form with the example of phenyl silatrane $1 \mathbf{k}$. 


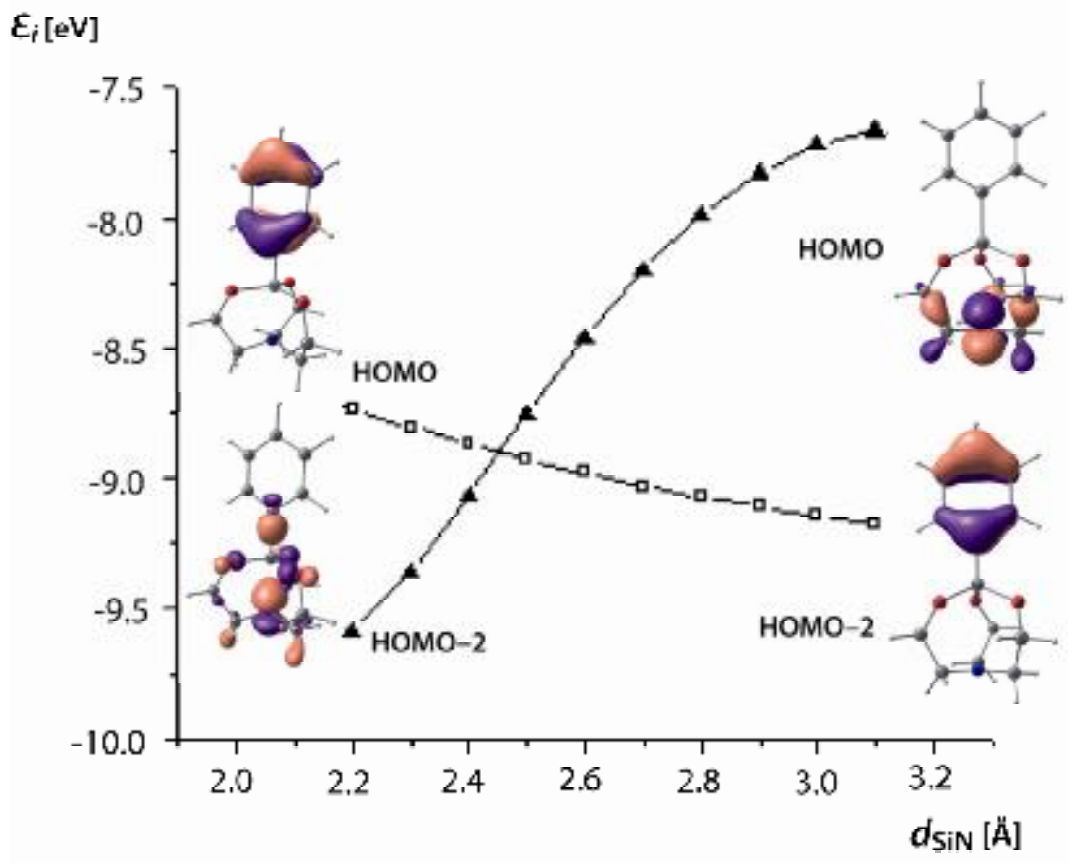

Figure 2. OVGF/6-311G(d,p)//B3PW91/6-311G(d,p) energies and structures of the key MOs (HOMO and HOMO-2) of Ph-silatrane (1k) as a function of the interatomic $\mathrm{Si} \cdots \mathrm{N}$ distance.

The MOs localized on the $\mathrm{N} \rightarrow \mathrm{SiX}$ moiety (HOMO and HOMO-2), differ essentially in their response (magnitude and sign of gradient of the orbital energy $\varepsilon_{i}$ ) to varying the length of the dative $\mathrm{N} \rightarrow \mathrm{Si}$ contact. This leads eventually to inversion of the key MOs and hence to a different type of HOMO in the equilibrium and non-equilibrium structures of $\mathbf{1 k}$ (Table 2). Note that the increase in $d_{\mathrm{SiN}}$ provokes an increase in the contribution of the $\mathrm{AO}$ of $\mathrm{N}_{\mathrm{s}}$ nitrogen to HOMO-2. For the nonequilibrium structure $\mathbf{1} \mathbf{k}^{\mathrm{n}-\mathrm{eq}} / / \mathbf{1} \mathbf{k}^{+\bullet(l)}$ with $d_{\mathrm{SiN}}=3.103 \AA$ (see Table 1 ), this orbital becomes HOMO that is mostly localized on $\mathrm{N}_{\mathrm{s}}$, in total agreement with the SD in $\mathbf{1} \mathbf{k}^{+\bullet(l)}$ (Figure $\mathbf{S 2}$ in ESI). There are strong reasons to suppose ${ }^{[21]}$ the demonstrated on $\mathbf{1} \mathbf{k}$ mechanism of the difference in the orbital structures of $\mathbf{1}$ and $\mathbf{1}^{\text {n-eq }}$ to be general for the vertical model of adiabatic ionization of all silatranes considered.

Entirely determined by the $\mathrm{X}$ nature in $\mathrm{XSi}\left(\mathrm{OCH}_{2} \mathrm{CH}_{2}\right)_{3} \mathrm{~N}$, the inversion of MOs can be realized (as in $\mathbf{1 h}, \mathbf{1 k}, \mathbf{1}, 1 \mathrm{o}$ and $\mathbf{1 r}$ ) or not $(\mathbf{1 a - 1 g}, \mathbf{1}, \mathbf{1 j}, \mathbf{1 m}$ and $\mathbf{1 q}$ ), and at this point, an a priori prediction of its likeliness during the transition from $\mathbf{1}$ to $\mathbf{1}^{\mathrm{n} \text {-eq }}$ is generally impossible.

In view of the above said it is interesting to take a closer look at the ionization of alkyl silatranes. In the case of methyl (1b) and ethyl (1c) silatranes, as was expected, it follows the $\mathbf{1} \rightarrow$ $\mathbf{1}^{+\bullet(l)}$ pathway, i.e. the electron transfer (ET) occurs from the $\mathrm{N}_{\mathrm{s}}$ atom. Very unexpectedly, the oxidation of $t$-butyl silatrane $\mathbf{1 d}$ leading to $\mathbf{1}^{+\bullet(s)}$ (with SD mostly localized on the Si-C bond, see Figure S1 in the Supporting Information) revealed to be energetically more favorable (Table 1) than 
that affecting the $\mathrm{N}_{\mathrm{s}}$ center. A particular feature of the structure of $\mathbf{1 d}$ is the remarkably longer Si-C bond as compared to that, e.g., in 1b (Table 1). As was shown by the NBO analysis, this is due to the exchange 4-electron repulsion between $\sigma$-orbitals of the $\mathrm{C}-\mathrm{H}$ and $\mathrm{C}-\mathrm{C}$ bonds of the $t$-Bu substituent and the orbitals of the equatorial plane $\mathrm{SiO}_{3}\left(\mathrm{n}_{\mathrm{O}}\right.$ and $\left.\sigma_{\mathrm{SiO}}\right)$ in $\mathbf{1 d}$, which is absent in $\mathbf{1 b}$. Substituting the Me group in $\mathbf{1 b}$ for $t$-Bu and imposing the constraint that $d_{\mathrm{SiC}}(\mathbf{1 b})=d_{\mathrm{SiC}}(\mathbf{1 d})$ results in substantial repulsive interactions $\left(\sigma_{\mathrm{CH}}, \mathrm{n}_{\mathrm{O}}+\sigma_{\mathrm{CC}}, \mathrm{n}_{\mathrm{O}}+\sigma_{\mathrm{SiO}}, \sigma_{\mathrm{CC}}>12 \mathrm{kcal} \mathrm{mol}^{-1}\right)$. Increasing the $\mathrm{SiC}$ distance up to its equilibrium $d_{\mathrm{SiC}}$ value in $\mathbf{1 d}$ remarkably (more than by $3 \mathrm{kcal} \mathrm{mol}^{-1}$ ) decreases the steric repulsion between the $t$-Bu group and the silatranyl core. The effect of stretching the SiC bond in $\mathbf{1 d}$ cardinally changes the relative position (leads to the inversion) of the levels of $\mathrm{N}_{\mathrm{s}}$ and SiC moieties: in 1d, HOMO is located on the Si-C bond and not on $\mathrm{N}_{\mathrm{s}}$ as in $\mathbf{1 b}$.

Adiabatic ionization of the "problem" anisyl and benzyl silatranes 1n and 1p (see Table 1) within the vertical model incites a special interest. Judging by the $\varepsilon_{i}$ values of HOMO for the non-

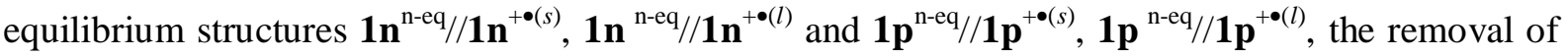
electron from 1n may occur with an equal easiness either from the $p-\mathrm{MeO}-\mathrm{C}_{6} \mathrm{H}_{4}$ substituent or from $\mathrm{N}_{s}$; in the case of $\mathbf{1 p}$, the oxidation on its benzyl fragment is preferred.

These conclusions are independent on the geometry optimization method (B3PW91 or MP2) (see Table 2) and are supported by the calculations of $\Delta G_{s-l}$ at the MP2//B3PW91 (but not MP2//MP2) level of theory (see Table 1). In this connection, let us mention that the problem of spin defect of the UMP2 functions is not concerned if the relative stabilities of the isomeric forms of RCs of silatranes are estimated by the OVGF energies of HOMO in their non-equilibrium structures and not by $\Delta G_{s-l}$.

\section{Potentials of electrooxidation of silatranes}

Experimental aspects: Peak potential $E_{\mathrm{p}}$, which is easily obtained form cyclic voltammetry $(\mathrm{CV})$, contains - besides a fundamental thermodynamic parameter of electron transfer (ET) $E_{0}$, - the contributions from kinetic and other (including experimental) factors. ${ }^{[22]}$ The primary steps of the oxidation of 1 corresponding to an EC mechanism and determining the actual value of $E_{\mathrm{p}}$ might be schematically outlined as:

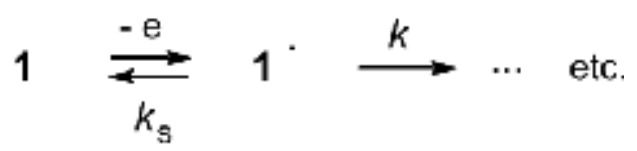

Scheme 2. Primary steps of electrooxidation of 1. 
The oxidation of $\mathbf{1}$ is mainly controlled by the kinetics of ET $\left(\mathrm{k}_{\mathrm{s}}\right)$ or/and by the follow-up chemical reaction $(\mathrm{k})$, which is reflected in $E_{\mathrm{p}}$. Therefore, direct comparison of $E_{\mathrm{p}}$ and $E^{0}$ is not quite correct. Meanwhile, the kinetic contributions in $E_{\mathrm{p}}$ with respect to $E^{0}$ are usually moderate for the processes not far from chemical reversibility (fast ET with relatively slow decay of the RCs), say of the order of several tens of $\mathrm{mV} .{ }^{[22 \mathrm{c}]}$ Moreover, a number of compounds with studied kinetics of the ensuing reactions of the RCs show close to ideal correlations of $E_{\mathrm{p}}$ and $E^{0}$ (passing through the origin with the slope practically of unity), see e.g. ${ }^{[23]}$.

It is to note that obtaining $E^{0}$ for redox systems (including silatranes) showing no distinct reversibility of voltammograms (a complementary to the main peak signal) is a special task in itself. $^{[22 b]}$

Electrooxidation of the majority of $\mathbf{1}$ is reversible or rather quasi-reversible (Figure 3, also see $^{[3]}$ ) which reflects important structural changes accompanying ET. When increasing the scan rate $v$, a complete reversibility $\left(i_{\mathrm{p}}{ }^{\text {red }} / i_{\mathrm{p}}{ }^{\text {ox }}=1\right)$ is never attained; on the contrary, ET becomes the limiting step at $v>2-5 \mathrm{~V} \mathrm{~s}^{-1}\left(E_{\mathrm{p}}-E_{\mathrm{p} / 2}>100-300 \mathrm{mV}\right)$.

When combining literature $E_{\mathrm{p}} \mathrm{s}$ with new experimental values, a certain divergence in the results may arise from the uncertainty in the potential of the reference electrode, ${ }^{[24]}$ undefined scan rate $^{[3]}$ and different electrode material. ${ }^{[22 \mathrm{a}]}$ In order to minimize it, the newly obtained $E_{\mathrm{p}} \mathrm{s}$ were referred to the same reference electrode as $\mathrm{in}^{[3 \mathrm{~b}]}$ and checked vs. $\mathrm{Fc}^{+} / \mathrm{Fc}$ reversible couple. ${ }^{[25]}$ At both electrodes, GC (used in ${ }^{[3]}$ ) and $\mathrm{Pt}$ (this work), all silatranes give distinct oxidation peaks, albeit better shaped at Pt (Figure 3). Since for a reversible ET the electrode nature is not important, the distortion of the peak shape might arise from adsorptional interactions often observed for organoelement compounds; ${ }^{[26]}$ therefore we sorted out and used closer to the ideal shape voltammograms obtained at both electrodes (Table 3).

As an example, cyclic voltammograms of oxidation of $\mathbf{1 i}$ in $\mathrm{CH}_{3} \mathrm{CN} / 0.1 \mathrm{M} \mathrm{Bu}_{4} \mathrm{BPF}_{6}$ at a $\mathrm{Pt}$ disk electrode are shown in Figure 3. Its limiting peak current $i_{\mathrm{p}}$ is linear with the scan rate and the concentration $\left(i_{\mathrm{p}} / C v^{1 / 2}=\right.$ const for $\left.v<2-5 \mathrm{~V} \mathrm{~s}^{-1}\right)$ as is typical for diffusion-controlled processes; ${ }^{\text {[22b] }}$ the electron stoichiometry is $\mathrm{n}=1$ (combining $i_{\mathrm{p}} / v^{1 / 2}$ with Cottrell slope $i \mathrm{t}^{1 / 2[27]}$ and from comparison with 1e $i_{\mathrm{p}}$ of $\mathrm{Fc}$ ). The process at low $v$ (Figure 3) might be characterized as electrochemically reversible and chemically irreversible: fast ET followed by a fast chemical reaction of $1 \mathbf{i}^{+\bullet} \cdot{ }^{[22 \mathrm{c}]}$ At higher $v\left(>1-2 \mathrm{~V} \mathrm{~s}^{-1}\right)$, kinetics of ET starts limiting the process $\left(E_{\mathrm{p}}-E_{\mathrm{p} / 2}>50\right.$ $70 \mathrm{mV}$ ) so as full reversibility could not be attained. With this, pulse voltammetry (Figure 4) permits visualizing the electrochemical reversibility of the $\mathbf{1 i}^{\mathbf{+}^{\bullet}} / \mathbf{1} \mathbf{i}$ system during the oxidation of $\mathbf{1 i}$. Similar behavior was observed for other silatranes, e.g. 1d and $\mathbf{1 l}$ (Figure 4). For all silatranes there is usually a second oxidation peak at about $300-500 \mathrm{mV}$ more positive potentials (Figure 4) supposedly corresponding to further oxidation of the primary RCs. 


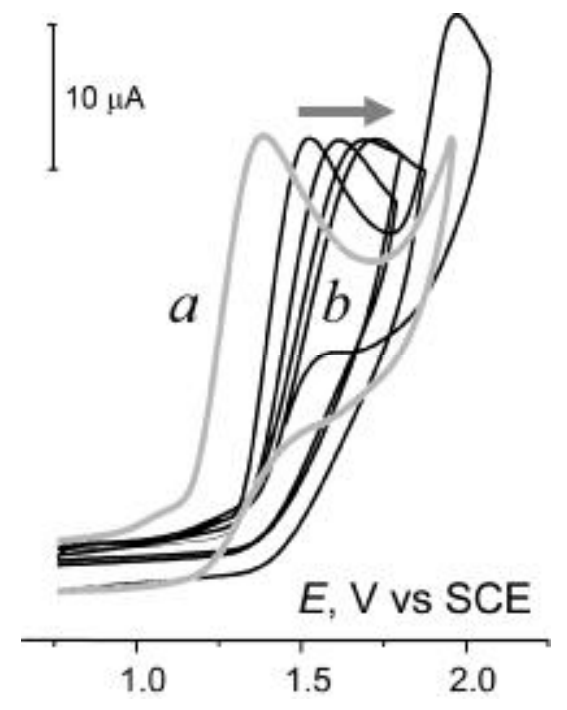

Figure 3. Surface and scan rate-normalized cyclic voltammograms of oxidation of $1 \mathbf{i}$ in $\mathrm{CH}_{3} \mathrm{CN} / 0.1$ $\mathrm{M} \mathrm{Bu}_{4} \mathrm{NPF}_{6}$ at a) $\mathrm{GC}$ and b) Pt disk electrodes. $\mathrm{T}=293 \mathrm{~K}$. The arrow shows the peak evolution (increasing control by the rate of ET) upon increasing the scan rate for $v=0.05,2,5$ and $10 \mathrm{~V} \mathrm{~s}^{-1}$.

Although Cl-silatrane was reported as not oxidizable, ${ }^{[3]}$ both halo-derivatives $\mathbf{1 g}$ and $\mathbf{1 h}(\mathrm{X}$ $=\mathrm{Cl}, \mathrm{Br}$ ) show distinct oxidation peaks at most positive in this reaction series potentials (Table 3).

To our great surprise, Fc used as an internal standard revealed to be non-innocent towards several $\mathbf{1}^{+\bullet} / \mathbf{1}$ systems: once the oxidation of the silatrane is attained, a new reversible redox pair appears at less anodic potentials (Figure 5 a, c). Quite intriguing, only silatranes with preferred $\mathbf{1}^{\bullet \bullet(l)}$ (i.e. with $\mathrm{N}_{\mathrm{s}}$ atom available for external coordination) show this feature while those, which, according to the vertical model of adiabatic ionization, should give $\mathbf{1}^{+\bullet(s)}$ (Table 2), do not (Figure 5, e). At this point, the exact nature of the species responsible for this new redox system is not clear. The ET interaction of $\mathbf{1}^{+\bullet}$ with Fc obviously needs relatively stable RCs and is not instantaneous since $\mathrm{Et}_{3} \mathrm{~N}$ or $\left(\mathrm{HOCH}_{2} \mathrm{CH}_{2}\right)_{3} \mathrm{~N}$ (chemically irreversible oxidation) do not form a similar redox system with Fc. This feature can be used for easy experimental probing the nature of RCs formed through the electrooxidation of silatranes and supposedly, of other metallatranes $\mathrm{XM}\left(\mathrm{OCH}_{2} \mathrm{CH}_{2}\right)_{3} \mathrm{~N}$, $\mathbf{I},(\mathrm{M}=\mathrm{Ge}, \mathrm{Sn}, \ldots)$. 


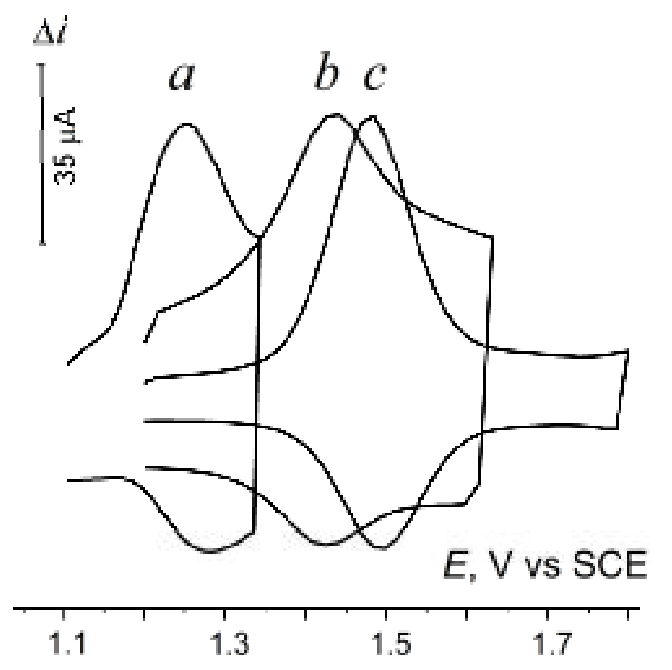

Figure 4. Square-wave pulse cyclic voltammetry of a) $\mathbf{1 i}$, b) $\mathbf{1 d}$ and c) $\mathbf{1 l}$ at a Pt disk electrode in $\mathrm{CH}_{3} \mathrm{CN} / 0.1 \mathrm{M} \mathrm{Bu}_{4} \mathrm{NPF}_{6}$. Pulse: $25 \mathrm{mV}$ per $0.01 \mathrm{~s}$, step high: $\mathrm{E}_{\mathrm{H}}=20 \mathrm{mV}, v=1 \mathrm{~V} \mathrm{~s}^{-1} . \mathrm{T}=295 \mathrm{~K}$.

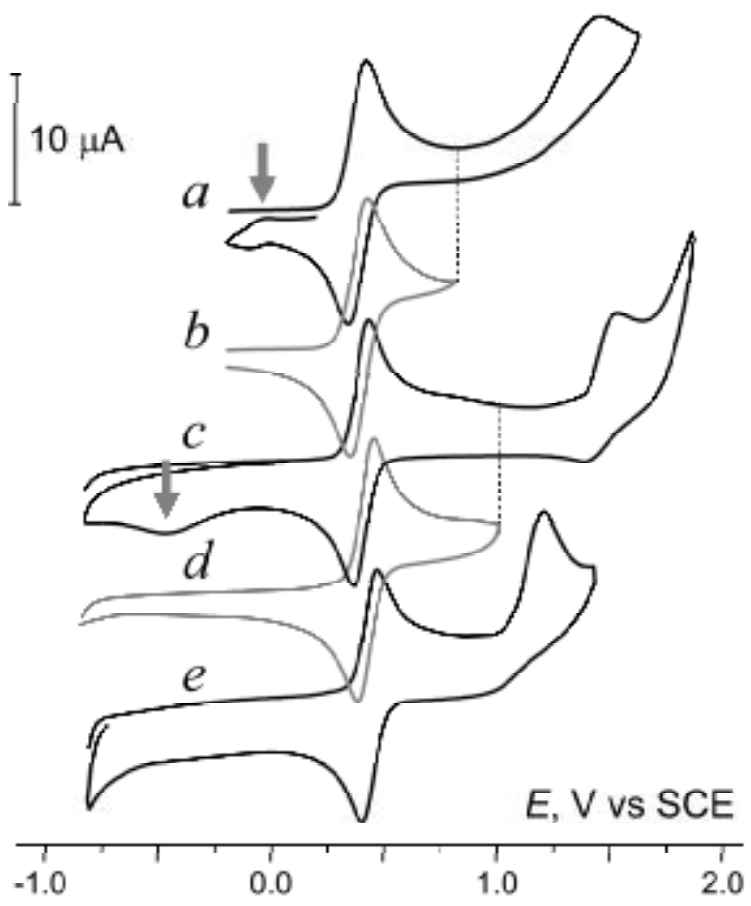

Figure 5. Cyclic voltammetry of $\mathrm{Fc}\left(2 \mathrm{mmol} \mathrm{L}^{-1}\right)$ in $\mathrm{CH}_{3} \mathrm{CN} / 0.1 \mathrm{M} \mathrm{Bu}_{4} \mathrm{NPF}_{6}$ at a Pt electrode in the presence of $\mathbf{1 i}(\mathrm{a}, \mathrm{b}), \mathbf{1 l}(\mathrm{c}, \mathrm{d})$ and $\mathbf{1 p}(\mathrm{e})$. (b) And (d) are the same as (a) and (c), respectively, but with the vertex potentials set before the oxidation peaks of the corresponding silatranes. $v=0.1 \mathrm{~V} \mathrm{~s}^{-}$ 1. $\mathrm{T}=293 \mathrm{~K}$.

Theoretical aspects: For 18 silatranes, a good agreement of the experimental $E_{p}$ with $E^{0}$, which were calculated at different levels of theory (taking into account the relative stability of RCs $\mathbf{1}^{\bullet \bullet(l)}$ and $\mathbf{1}^{+\bullet(s)}$; Table 1), was achieved (Table 3, Figure 6) with the MP2 estimation of energy on the 
B3PW91 optimized geometries $(M A E=0.03)$; the MP2//MP2 treatment performed a bit poorer $(M A E=0.05)$ (see the Experimental aspects on the problem of considering $E_{p}$ vs $\left.E^{0}\right)$.

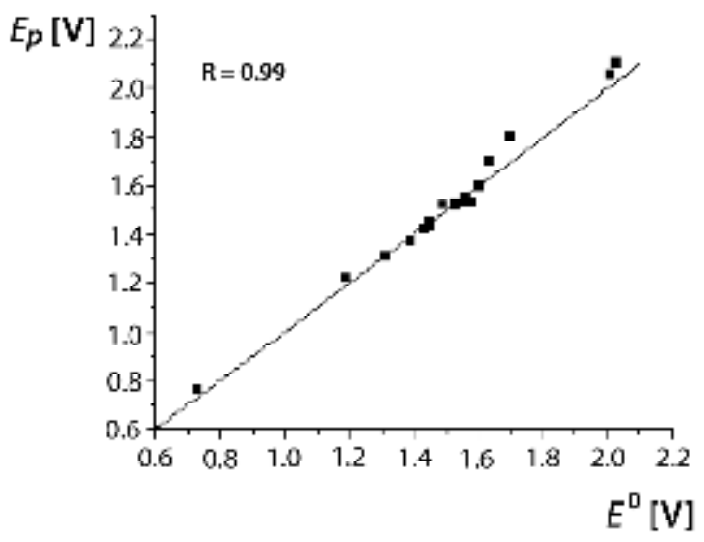

Figure 6. Interrelation ("ideal" is given by the solid line) of the experimental peak potentials $\left(E_{\mathrm{p}}\right)$ and the MP2//B3PW91 calculated potentials $\left(E^{0}\right)$ of the oxidation of silatranes $\mathbf{1}$ in acetonitrile.

Quite surprisingly, the $E^{0}$ calculated using the recommended in literature Equations $(2)^{[28]}$ and especially (3) ${ }^{[29]}$ (see the Computational Methods) did not well reproduce the experimental $E_{p}$. Moreover, the quality of $E^{0}$ was substantially poorer than even of those obtained at the B3PW91/6$311 \mathrm{G}(\mathrm{d}, \mathrm{p})$ level (Table 3). Obviously, the procedure of separation of the gas phase and solvation contributions to $\Delta G^{0}$ ox within the approaches (2) and (3) is not appropriate for the silatranes with high sensitivity of the geometry to the media effects. ${ }^{[8-11]}$

Table 3. Experimental $\left(E_{\mathrm{p}}\right)$ and calculated $\left(E^{0}\right)$ at different levels of theory potentials of electrooxidation ([V] vs. SCE) of silatranes $\mathrm{XSi}\left(\mathrm{OCH}_{2} \mathrm{CH}_{2}\right)_{3} \mathrm{~N}$ in $\mathrm{CH}_{3} \mathrm{CN}$ and experimental peak half-widths $\left(E_{\mathrm{p}}-E_{\mathrm{p} / 2}[\mathrm{mV}]\right)$.

\begin{tabular}{lllllllc}
\hline $\mathrm{X}$ & Exp. $^{[a]}$ & $E_{\mathrm{p}}-E_{\mathrm{p} / 2}$ & $\begin{array}{l}\text { MP2// } \\
\text { B3PW91 }\end{array}$ & $\begin{array}{l}\text { MP2// } \\
\text { MP2 }\end{array}$ & $\begin{array}{l}\text { B3PW91// } \\
\text { B3PW91 }\end{array}$ & Eq. (2) & Eq. (3) \\
\hline $\mathrm{H}$ & $1.70^{[b]}$ & - & 1.63 & 1.63 & 1.33 & 1.11 & 0.56 \\
$\mathrm{Me}$ & $1.43^{[b]}$ & 68 & 1.45 & 1.42 & 1.11 & 0.88 & 0.35 \\
$\mathrm{Et}$ & $1.42^{[b]}$ & - & 1.43 & 1.43 & 1.09 & - & - \\
$t \mathrm{-Bu}$ & 1.22 & 65 & 1.19 & 1.18 & 1.03 & - & - \\
$\mathrm{MeO}$ & $1.53^{[b]}$ & - & 1.58 & 1.57 & 1.31 & - & - \\
$\mathrm{EtO}$ & $1.53^{[b]}$ & - & 1.56 & 1.57 & 1.29 & 1.06 & -
\end{tabular}




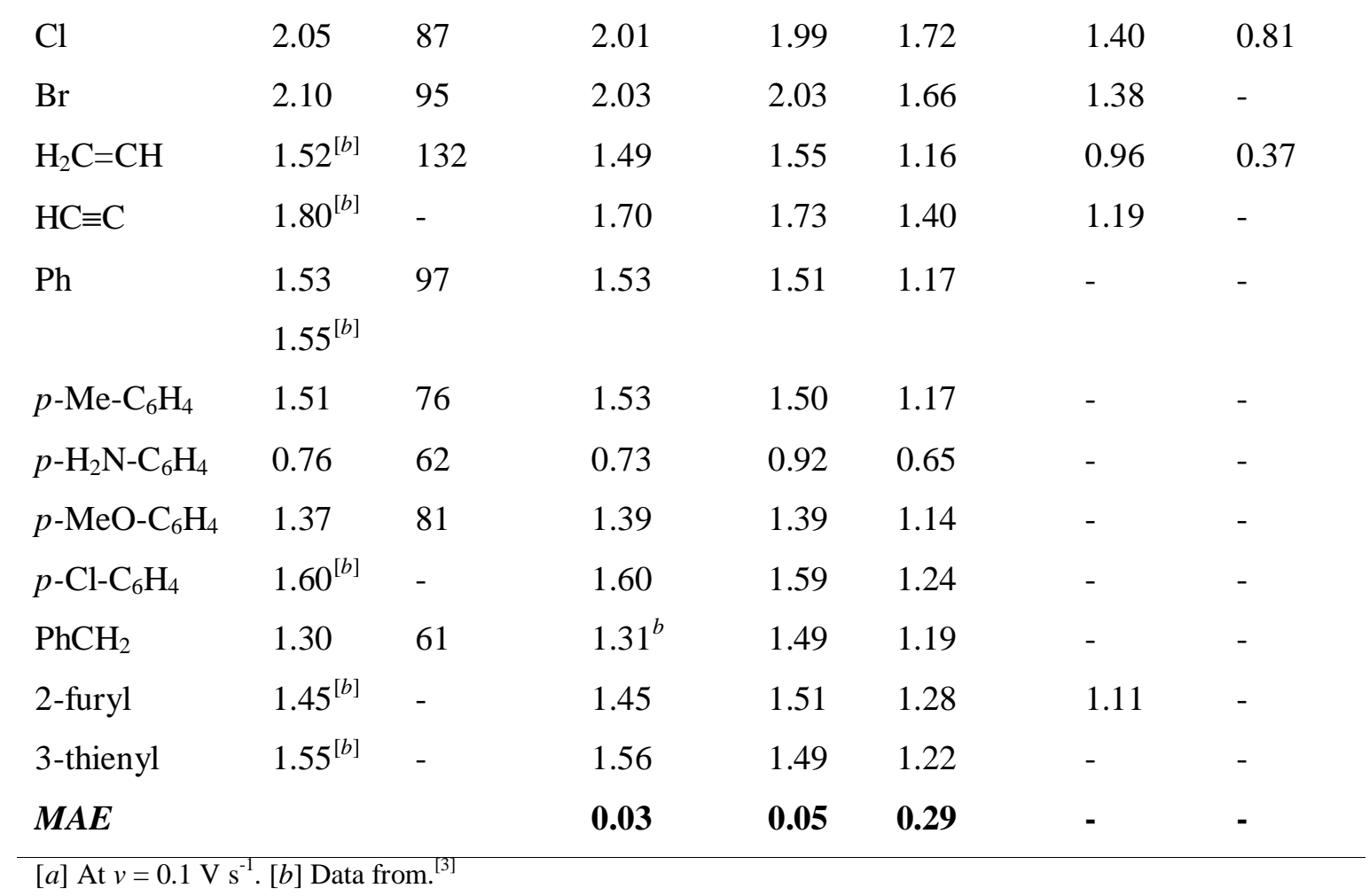

In line with what was mentioned earlier, ${ }^{[3]}$ the "proper" (i.e. affecting the $\mathrm{N}_{\mathrm{s}}$ ) oxidation of 13 silatranes (1a-1c, 1e-11, 10 and 1r) occurs at remarkably more positive potentials $\left(E_{p}=1.43-\right.$ $2.031 \mathrm{~V}$; Table 3), than that of the model amines in which nitrogen is not involved in the dative $\mathrm{N} \rightarrow$ Si bonding (e.g. for $\left.\mathrm{N}\left(\mathrm{CH}_{2} \mathrm{CH}_{2} \mathrm{OH}\right)_{3} E_{p}=0.90 \mathrm{~B}^{[3]}\right)$. Note that $p-\mathrm{H}_{2} \mathrm{~N}-\mathrm{C}_{6} \mathrm{H}_{4}$-silatrane $1 \mathbf{m}\left(E_{p}=\right.$ $0.76 \mathrm{~V}$ ) should be considered as a silylated aniline where silatranyl moiety is not concerned by ET and only acts as a substituent.

Theoretical considerations suggest ${ }^{[21 b]}$ the shift of $E^{0}$ of a "proper" oxidized silatrane with respect to a model $\mathrm{NR}_{3}$ to be dependent on the intensity of $\mathrm{N} \rightarrow \mathrm{Si}$ coordination when varying $\mathrm{X}$.

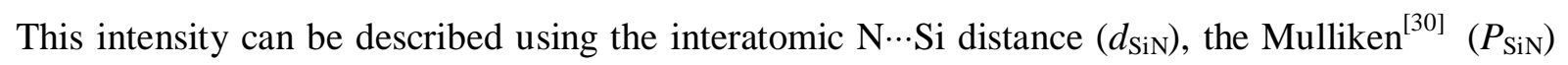
and Wiberg ${ }^{[31]}\left(W_{\mathrm{SiN}}\right)$ populations of the $\mathrm{N} \rightarrow \mathrm{Si}$ contact, the NBO energy of the bonding interaction between the $\mathrm{N}_{\mathrm{s}}$ lone pair (LP) and the antibonding orbital of the $\mathrm{Si}-\mathrm{X}$ bond obtained as a second order perturbation energy $\left(E(2)\left[\mathrm{n}_{\mathrm{N}}, \sigma^{*} \mathrm{SiX}\right]\right)$, the AIM energy of the $\mathrm{N} \rightarrow \operatorname{Si}$ interaction $\left(E_{\mathrm{SiN}}\right)$, the degree of the electron density transfer from the nitrogen LP orbital $\left(\Delta N\left[\mathrm{n}_{\mathrm{N}}\right]\right)$ to an acceptor moiety $\mathrm{XSiO}_{3}$ during the formation of the $\mathrm{N} \rightarrow \mathrm{Si}$ bond, and others. ${ }^{[21 \mathrm{~b}]}$ All these strength characteristics of the $\mathrm{N} \rightarrow \mathrm{Si}$ bond, as a rule, vary in a consistent manner with the variation of $\mathrm{X} .{ }^{[21 \mathrm{~b}]}$ Therefore one could expect the potentials of the "proper" oxidation of $\mathbf{1}$ to be closely related to the geometrical, energetic, electronic and orbital parameters of the $\mathrm{N} \rightarrow \mathrm{Si}$ attractive interaction in the parent neutral molecule. 
Indeed, the correlations of $\mathrm{E}^{0}$ with, for example, $d_{\mathrm{SiN}}, \mathrm{P}_{\mathrm{SiN}}$ and $E_{\mathrm{SiN}}$ turned out to be quite satisfactory (Figure 7, Table S4 in the Supporting Information)). They corroborate the intuitively expected $^{[3,4 c]}$ trend of weakening the ionization ability of $\mathrm{N}_{\mathrm{s}}$ upon strenghening the $\mathrm{N} \rightarrow \mathrm{Si}$ coordination (i.e. decreasing $d_{\mathrm{SiN}}$ and increasing $\mathrm{P}_{\mathrm{SiN}}$ and $E_{\mathrm{SiN}}$ ). It is then not surprising that halosilatranes $\mathbf{1 g}$ and $\mathbf{1 h}$, possessing the strongest $\mathrm{N} \rightarrow \operatorname{Si}$ bond in the family $\mathbf{1}$, are much more difficult to oxidize than other silatranes (Table 1,3 ).

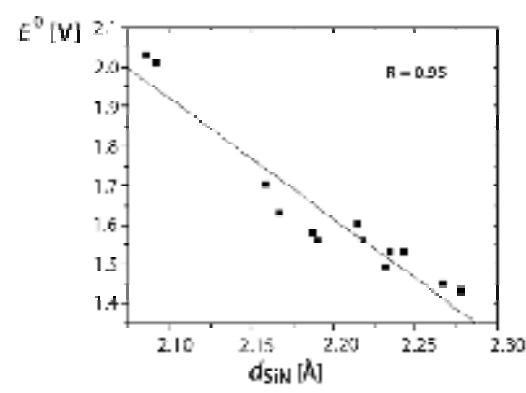

a

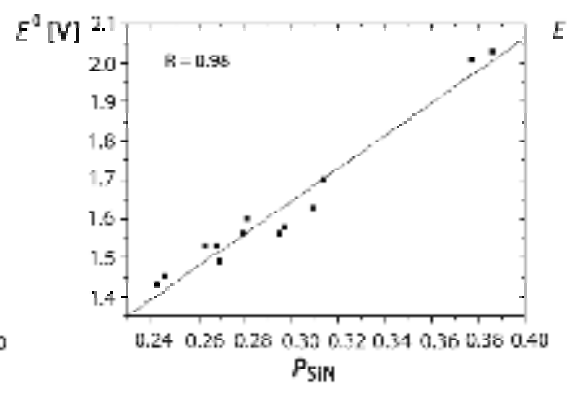

b

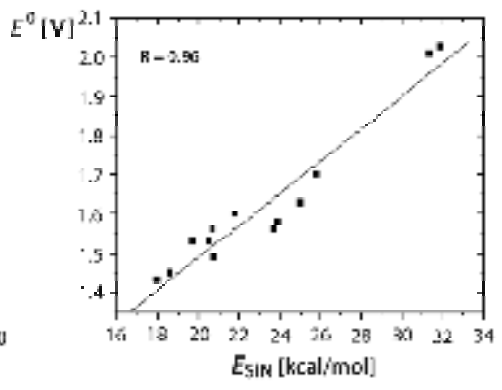

$c$

Figure 7. Dependence of $E^{0}$ for the "proper" oxidized silatranes $\mathrm{XSi}\left(\mathrm{OCH}_{2} \mathrm{CH}_{2}\right)_{3} \mathrm{~N}$ on a) the interatomic $\mathrm{Si} \cdots \mathrm{N}$ distance, $\left.d_{\mathrm{SiN}}, \mathbf{b}\right)$ the Mulliken $\mathrm{SiN}$ bond order $\mathrm{P}_{\mathrm{SiN}}$, and $\mathbf{c}$ ) the AIM energies of the $\mathrm{N} \rightarrow \mathrm{Si}$ dative contact $E_{\mathrm{SiN}}$.

Another quick tool for predicting the redox properties of substrates could be considering the inductive Taft constants $\sigma^{*},{ }^{[32]}$ often used in organic electrochemistry. ${ }^{[33]}$ For silatranes $\mathbf{1}$, this can be justified by the linear correlation between $d_{\mathrm{SiN}}$ and $\sigma^{*}$ of the $\mathrm{X}$ substituent in solid state (X-ray), obtained for a relatively narrow series of $1 .^{[8,34]}$ Unfortunately, the $E^{0}(\mathbf{1})-\sigma^{*}$ correlation (Figure 8) turned out to be unsatisfactory (just as that earlier obtained for another number of silatranes) ${ }^{[3]}$ which obviously stems from not taking into account the mesomeric, steric and polarization ${ }^{[35]}$ effects of X. It is to be noted that obtaining the correct estimations of $\sigma^{*}$ for the $\mathrm{X}$ substituent at the Si center is quite difficult. ${ }^{[32]}$ 


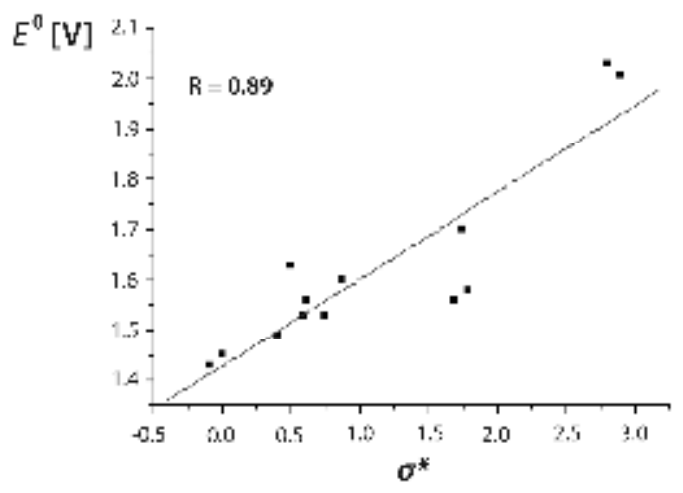

Figure 8. Calculated $E^{0}$ of "proper" oxidation of $\mathrm{XSi}\left(\mathrm{OCH}_{2} \mathrm{CH}_{2}\right)_{3} \mathrm{~N}$ vs. $\sigma^{*}$ constants of substituents $\mathrm{X}$.

As a measure of strength of the dative $\mathrm{N} \rightarrow \mathrm{Si}$ bond in silatranes, in addition to the above mentioned geometrical, energetic, electronic and orbital characteristics, one may also use its NMR parameters, particularly, the values of isotropic ${ }^{15} \mathrm{~N}$ chemical shifts $\left(\delta_{\mathrm{N}}\right)$ of the donor nitrogen atom. ${ }^{[8,9,36]}$ Moreover, the good linear relationship: ${ }^{[9]}$

$$
\delta_{\mathrm{N}}=-252.41-47.07 d_{\mathrm{SiN}}(\mathrm{R}=0.99)
$$

is common for crystals, gases, and solutions of silatranes $\mathrm{XSi}\left(\mathrm{OCH}_{2} \mathrm{CH}_{2}\right)_{3} \mathrm{~N}$ at any substituent $\mathrm{X}$. ${ }^{[9]}$ This equation allows, using the solution experimental values $\delta_{\mathrm{N}}$ for $\mathbf{1}$, to obtain the solution $d_{\mathrm{SiN}}$ values and, as shown above, relatively surely predict the values of "proper" oxidation potentials of silatranes.

The results of this study are expected to be of general character and useful for further developing redox chemistry of other hypervalent derivatives of silicon and of its neighbors in the group 14 (Ge and $\mathrm{Sn})$.

\section{Conclusion}

Using 18 silatranes $\mathrm{XSi}\left(\mathrm{OCH}_{2} \mathrm{CH}_{2}\right)_{3} \mathrm{~N}$ (1) as an example, the potentials of electrochemical oxidation $E^{0}$ of the hypervalent compounds of Si with particularly anomalous sensitivity to the medium effects were calculated for the first time. The contribution of the Gibbs free energy difference $\Delta G_{o x}^{0}$ between the neutral molecule and its RC to $E^{0}$, (eq. 1) was estimated by the B3PW91//B3PW91, MP2//B3PW91 and MP2//MP2 methods, respectively, with the 6-311G(d,p), $6-311 \mathrm{G}(2 \mathrm{~d}, \mathrm{p})$ and, in some cases, with the $6-311++\mathrm{G}(3 \mathrm{df}, 3 \mathrm{pd})$ basis sets. Besides these, the recommended $^{[28,29]}$ protocols (2) and (3) using the high level methods CBS-QB3 and G3(MP2)RAD for assessing the gas phase term in $\Delta G_{o x}^{0}$ were also applied. 
The experimental values $E_{\mathrm{p}}$ for 11 silatranes were taken from the literature and previously unknown potentials for the remaining 7 structures, including 1 with $\mathrm{X}=\mathrm{Cl}, \mathrm{Br}$, were obtained using voltammetry. An excellent agreement of $E_{\mathrm{p}}$ (acetonitrile) and $E^{0}$ (C-PCM) was achieved using the MP2//B3PW91 approach $(M A E=0.03)$. The MP2//MP2 method performed a little poorer $(M A E=$ 0.05). Surprisingly, the high level methods according to eq. (2) and in particular to eq. (3) very unsatisfactorily accounted for $E^{0}$ : the quality of thus obtained $E^{0}$ was even worse than that obtained from the B3PW91/6-311G(d,p) calculations $(M A E=0.29)$.

The calculations revealed a "bond stretch isomerism" of the $\mathrm{N} \rightarrow \mathrm{Si}$ dative bond in RCs of 1. The "isomers" $\mathbf{1}^{+\bullet(s)}$ with the short coordination contact NSi $\left(d_{\mathrm{SiN}}<2.13 \AA\right)$ have a high pentacoordinate character of Si and the spin density localized on the substituent $\mathrm{X}$ (or on the X-Si bond). In complementary "isomers" $\mathbf{1}^{+\bullet(l)}$ with the long $\mathrm{N} \rightarrow \mathrm{Si}$ distance $\left(d_{\mathrm{SiN}}>3.0 \AA\right)$, silicon is

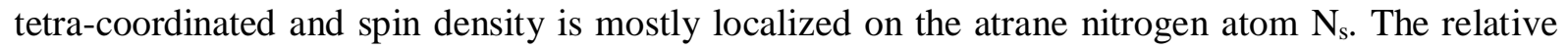
stabilities of $\mathbf{1}^{+\bullet(s)}$ and $\mathbf{1}^{+\bullet(l)}$ are dependent on the nature of $\mathrm{X}$ and are, as a rule, hard to predict.

Based on the type of HOMO in the neutral molecules 1 it is impossible, in the general case, to predict the most probable direction of their adiabatic ionization; $1 \rightarrow \mathbf{1}^{+\bullet(s)}$ or $\mathbf{1} \rightarrow \mathbf{1}^{+\bullet(l)}$. The reason of this is the inversion of the key MOs of the $\mathrm{N} \rightarrow \mathrm{SiX}$ system during its ET-induced anomalous geometric rearrangement. The reliable prognostics of the localization of SD upon electron withdrawal in the silatranes family is possible within the proposed vertical model of adiabatic ionization, considering the OVGF energies of HOMOs for the non-equilibrium structures of $\mathbf{1}^{\text {n-eq }}$ with the geometries of $\mathbf{1}^{+\bullet(s)}$ and $\mathbf{1}^{+\bullet(l)}$. Depending on the nature of $\mathrm{X}$, the inversion of

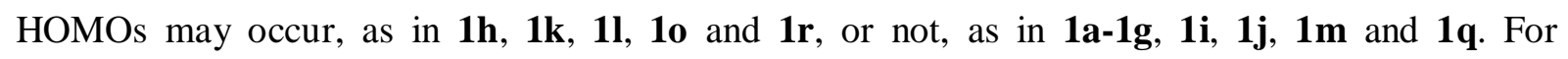
determining the center of localization of the unpaired electron in RCs of silatranes, a good practical tool seems to be the test of electrooxidation of $\mathbf{1}$ in the presence of ferrocene.

The relationships of $E_{0}$ of "proper" oxidation of $\mathrm{XSi}\left(\mathrm{OCH}_{2} \mathrm{CH}_{2}\right)_{3} \mathrm{~N}$ (with $\mathrm{N}_{\mathrm{s}}$ providing the electron to be removed) with geometrical, energetic, electronic and orbital characteristics of the $\mathrm{N} \rightarrow$ Si dative contact were established. They provide the reliable theoretical base for the intuitively expected trend of weakening the ionization ability of $\mathrm{N}_{\mathrm{s}}$ upon strengthening the $\mathrm{N} \rightarrow \mathrm{Si}$ coordination.

\section{Experimental Section}

\section{Electrochemistry}

Electrochemical measurements (cyclic and square wave pulse voltammetry and double step chronoamperometry) for 8 silatranes (1d, 1g, 1h, 1k-n, 1p) were carried out in a three-electrode configuration using a scanning electronic potentiostat PAR 2273 driven under PowerSuite (PAR) program package. Glassy carbon (GC) disk of $2.4 \mathrm{~mm}$ diameter and a Pt disk $(0.5 \mathrm{~mm})$ were used as working electrodes. A GC rod $(2.5 \times 75 \mathrm{~mm})$ served as an auxiliary electrode and a silver wire 
electrolytically covered with $\mathrm{AgCl}$ was used as a reference electrode. The counter and the reference electrodes were separated from the analyte with an electrolytic bridge filled with $\mathrm{CH}_{3} \mathrm{CN} / 0.1 \mathrm{M}$ $\mathrm{Bu}_{4} \mathrm{NPF}_{6}$. The experimental curves were corrected for ohmic drops using IR-compensating facility of the potentiostat. Peak potentials $E_{\mathrm{p}}$ and peak currents $i_{\mathrm{p}}$ of silatranes were additionally checked using reversible system ferricenium/ferrocene $\left(\mathrm{Fc}^{+} / \mathrm{Fc}\right)$ in the same solution $\left({E^{0}}_{(\mathrm{Fc}}^{0} / \mathrm{Fc}\right)=0.31 \mathrm{vs}$. $\left.\mathrm{SCE},{ }^{[25]} \mathrm{n}=1\right)$.

Tetrabutylammonium salts $\mathrm{Bu}_{4} \mathrm{NPF}_{6}$ or $\mathrm{Bu}_{4} \mathrm{NBF}_{4}$ (ACROS), activated in vacuum for $10 \mathrm{hrs}$ at $80{ }^{\circ} \mathrm{C}$ and prepared as a $0.1 \mathrm{M}$ solution, were used as supporting electrolytes. 1-X silatranes were synthesized according to known procedures. ${ }^{[5]}$

\section{Computational Methods}

The oxidation potentials of silatranes 1, $E^{0}$, were calculated using Equation (1) ${ }^{[37]}$ taking into account the experimental conditions (solvent, reference electrode, temperature).

$$
E^{0}=\frac{\Delta G_{o x}^{0}}{n F}+E_{S C E}
$$

here $n$ stands for the number of electrons transferred ( $n=1$ in this case), $F$ is Faraday constant, $E_{\mathrm{SCE}}$ is the absolute potential of saturated calomel electrode in acetonitrile $\left(E_{\mathrm{SCE}}=-4.67 \mathrm{~V}\right){ }^{[29]}$ and $\Delta G_{o x}^{0}$ is the difference in the Gibbs free energies of the molecule and its radical cation in $\mathrm{CH}_{3} \mathrm{CN}$ at $\mathrm{T}=$ $298 \mathrm{~K}$; this term also includes a correction for the integrated heat capacity for the free electron $\left(0.752 \mathrm{kcal} \mathrm{mol}^{-1}\right) .{ }^{[28,29,38]}$

The geometries of 1 were optimized in the restricted variants of the MP2/6-311G(2d,p) and B3PW91/6-311G(d,p $)^{[39]}$ methods and the unrestricted variants of these methods were applied for geometry optimizations for species $\mathbf{1}^{\bullet+}$, according to literature data. ${ }^{[9,21 \mathrm{~b}]}$

The MP2//B3PW91 and MP2//MP2 levels of theory with the 6-311G(d,p), 6-311G(2d,p) and, in several cases, 6-311++G(3df,3pd) basis sets were used for assessing $\Delta G_{o x}^{0}$ and the relative stability of isomers $\mathbf{1}^{\bullet+}\left(\Delta G_{s-l}^{0}\right.$, difference in their Gibbs free energies). The Method2//Method1 notation implies that the calculation of property was performed with the Method2 for a structure optimized with Method1.

The influence of solvation on the structures of $\mathbf{1}$ and $\mathbf{1}^{\mathbf{*}}$ has been mostly accounted for within the continuum C-PCM ${ }^{[40 a, b]}$ model both at the $\mathrm{MP}^{[40 \mathrm{c}]}$ and DFT levels of theory; in certain cases, COSMO,${ }^{[41]}$ IEF-PCM,${ }^{[42]}$ and SMD $^{[43]}$ approaches were also used.

In the literature it has been proposed to separate the gas phase and solvation contributions to $\Delta G^{0}{ }_{\text {ox }}$ (eq. 1) using Equations (2) ${ }^{[28]}$ and (3). ${ }^{[29]}$ The first one is to be calculated at the high level of theory while the second at the lower level. 
$\Delta G_{\text {ox }}^{0}=\Delta G_{g}{ }^{0}(\mathrm{CBS}-\mathrm{QB} 3)+\Delta \Delta G_{s}^{0}(\mathrm{SMD}$ M06-2X/6-31G(d))

$\Delta G_{\text {ox }}^{0}=\Delta G_{g}{ }^{0}(\mathrm{G} 3(\mathrm{MP} 2)-\mathrm{RAD})+\Delta \Delta G_{s}{ }^{0}(\mathrm{CPCM} \mathrm{HF}($ or B3LYP $) / 6-31+\mathrm{G}(\mathrm{d}))$

Here $\Delta G_{g}{ }^{0}$ is the difference in the Gibbs free energies of the RC and the neutral molecule in the isolated state at $\mathrm{T}=298 \mathrm{~K}$, while $\Delta \Delta G_{s}{ }^{0}$ is the difference in their solvation energies in $\mathrm{CH}_{3} \mathrm{CN}$. The mean absolute error in $E^{0}$ calculated through eq. (2) was reported to be $0.13 \mathrm{~V}^{[28]}$ and $0.07 \mathrm{~V}^{[29]}$ if eq. (3) was used. This prompted us to test the approaches (2) and (3) on the intramolecular complexes $\mathbf{1}$ whose geometry, contrary to the earlier studied systems, ${ }^{[28,29]}$ is anomalously sensitive to the medium effects and therefore to the methods of its calculation. ${ }^{[8,9]}$

All calculated structures correspond to the minima on the potential energy surface (PES) as was confirmed by the positive eigenvalues of the corresponding hessians.

The problem of spin contamination for the UMP2 wave functions in the RCs with $\left\langle S^{2}\right\rangle$ (the spin-squared expectation value) deviated from 0.75 by more than $10 \%^{[15]}$ was resolved using the spin-projection procedure (a PMP2 ${ }^{[44]}$ approach). In some cases, the restricted open-shell MP2 method (ROMP2) ${ }^{[45]}$ was employed.

The energies of molecular orbitals for $\mathbf{1}$ were obtained using the electron propagator $\mathrm{OVGF}^{[46]}$ method with the $6-311 \mathrm{G}(\mathrm{d}, \mathrm{p})$ basis set. In this method, the Hartree-Fock solutions are used as a zeroth approximation, and the many-body perturbation theory is applied to obtain the ionization energies accounting for the correlation and relaxation effects. The OVGF values of the $\mathrm{MO}$ energies for silatranes are about $1.5 \mathrm{eV}$ lower than the HF values, ${ }^{[21]}$ therefore for the correct description of the orbital structure of $\mathbf{1}$ it is necessary to apply the OVGF approach.

The Orca ${ }^{[47]}$ program was used for the COSMO solvation model calculations. The GAMESS $^{[48]}$ electronic structure code was employed for performing the ROMP2 calculations. The Mulliken population analysis was performed on the Hartree-Fock orbitals using the FIREFLY package. ${ }^{[49]}$ The NBO analysis ${ }^{[50]}$ was carried out using the NBO $5.0^{[51]}$ program via the FIREFLY ${ }^{[49]}$ interface on the $\mathrm{HF} / 6-311 \mathrm{G}(\mathrm{d}, \mathrm{p})$ molecular orbitals. All remaining calculations were carried out with Gaussian $09^{[52]}$ program package.

The $\operatorname{AIM}^{[53]}$ (Atoms In Molecules theory) estimation of the energy ${ }^{[54]}$ of the $\mathrm{N} \rightarrow$ Si dative contact $\left(E_{\mathrm{SiN}}\right)$ was carried out using the well-approved ${ }^{[55]}$ relationship: $E_{\mathrm{SiN}}=-V\left(\mathbf{r}_{\mathrm{c}}\right) / 2$; where $V\left(\mathbf{r}_{\mathrm{c}}\right)$ is the potential energy density at the bond critical point, $b c p(\mathrm{SiN})$. For this estimation we used the MP2(full)/6-311++G(d,p) electron distribution $\rho(\mathbf{r})$ of molecules $\mathrm{XSi}\left(\mathrm{OCH}_{2} \mathrm{CH}_{2}\right)_{3} \mathrm{~N}$ obtained with the MORPHY $1.0^{[56]}$ program. 
The pictures of MO and spin density distribution were generated using the ChemCraft program. ${ }^{[57]}$ The pentacoordinate character of the silicon atom (its trigonal bipyramidalization), $\eta_{e}$, was determined by Equation (4): ${ }^{[58]}$

$$
\eta_{e}=\left[1-\frac{120-1 / 3 \sum_{n=1}^{3} \theta_{n}}{120-109.5}\right] \times 100 \%
$$

here, $\theta_{n}$ refers to the bond angle between the equatorial bonds at Si.

As a statistical criterion for assessing the quality of calculations of the oxidation potentials of $\mathbf{1}$, we used the value of the mean absolute error (MAE), defined by (5):

$$
M A E=\frac{1}{n} \sum_{i=1}^{n}\left|E_{p_{i}}-E_{i}^{0}\right|
$$

here, $E_{\mathrm{p} i}$ and $E_{i}^{0}$ are the experimental and theoretical oxidation potentials, $n$ is the number of compared potentials.

\section{Acknowledgements}

We are grateful to Prof. P. L. A. Popelier for a copy of the MORPHY1.0 program, the Irkutsk Supercomputer Center of SB RAS for providing computational resources of the computational cluster "Academician V. M. Matrosov",[59] to perform calculations using the programs Orca, GAMESS, Firefly.

The authors declare no conflict of financial or other interests.

\section{References}

[1] C. Peureux, V. Jouikov, Chem. Eur. J., 2014, 20, 9290-9294.

[2] G. Cerveau, C. Chuit, E. Colomer, R. J. P. Corriu, C. Reye, Organometallics 1990, 9, 24152417.

[3] a) K. Broka, V.T. Glezer, J. Stradins, G. Zelcans, Zh. Obshch. Khim. 1991, 61, 1374-1378;

b) K. Broka, J. Stradins, V. Glezer, G. Zelcans, E. Lukevics, J. Electroanal. Chem. 1993, 351 199-206.

[4] a) S. Soualmi, L. Ignatovich, E. Lukevics, A. Ourari, V. Jouikov, ECS Trans. 2008, 13, 6369; b) S. Soualmi, L. Ignatovich, E. Lukevics, A. Ourari, V. Jouikov, J. Organomet. Chem. 2008, 693, 1346-1352; c) V. Jouikov, ECS Trans. 2010, 28, 5-16; d) S. Soualmi, L. Ignatovich, V. Jouikov, J. Appl. Organomet. Chem. 2010, 24, 865-871; e) L. Ignatovich and V. Jouikov, J. Organomet. Chem. 2014, 751, 546-554.

[5] Y. Wang, Synthèse, réactivité électrochimique et structure électronique de 1-Rmétallatranes $(M=S i, S n)$, Thesis, University of Rennes 1, 2012, p. 111. 
[6] T. Zöller, C. Dietz, L. Iovkova-Berends, O. Karsten, G. Bradtmöller, A. Wiegand, Y. Wang, V. Jouikov, K. Jurkschat, Inorg. Chem. 2012, 51, 1041-1056.

[7] K. G. Solymos, B. Varhegyi, E. Kalman, F. H. Karman, M. Gal, P. Hencsei, L. Bihatsi, Corr. Sci. 1993, 35, 1455-1462.

[8] V. Pestunovich, S. Kirpichenko, M. Voronkov, in The Chemistry of Organic Silicon Compounds, Vol. 2 (Eds.: Z. Rappoport, Y. Apeloig), Wiley, Chichester, UK, 1998, pp. 1447-1537.

[9] E. F. Belogolova, V. F. Sidorkin, J. Phys. Chem. A, 2013, 117, 5365-5376.

[10] M. W. Schmidt, T. L. Windus, M. S. Gordon, J. Am. Chem. Soc. 1995, 117, 7480-7486.

[11] a) V. A. Pestunovich, V. F. Sidorkin, M. G. Voronkov, in Progress in Organosilicon Chemistry, Chap. 5 (Eds.: B. Marcinies, J. Chojnowski), Gordon and Breach Science Publishers, Basel, 1995, pp. 69-82; b) I. F. Shishkov, L. V. Khristenko, F. M. Rudakov, A. V. Golubinskii, L. V. Vilkov, S. S. Karlov, G. S. Zaitseva, S. Samdal, Struct. Chem. 2004, 15, 11-16; c) V. F. Sidorkin, E. F. Belogolova, V. A. Pestunovich, J. Mol. Struct. (THEOCHEM) 2001, 538, 59-65; d) E. P. Doronina, V. F. Sidorkin, N. F. Lazareva, Organometallics 2010, 29, 3327-3340.

[12] a) J. G. Verkade, Coord. Chem. Rev. 1994, 137, 233-295; b) M. G. Voronkov, V. P. Baryshok, in Use of Silatranes for Medicine and Agriculture (Ed.: G. A. Tolstikov), Publishing House of the Siberian Branch of Russian Academy of Sciences, Novosibirsk, 2005; p. 258; c) J. K. Puri, R. Singh, V. K. Chahal, Chem. Soc. Rev. 2011, 40, 1791-1840.

[13] The propensity of pentacoordinate silicon species to electron donation upon oxidation was also demonstrated for silatranyl substituted ferrocenes, anionic catechol complexes and organopentafluorosilicates: a) G. Cerveau, C. Chuit, E. Colomer, R. J. P. Corriu, C. Reye, Organometallics 1990, 9, 2415-2417. b) V. Corcé, L.-M. Chamoreau, E. Derat, J.-P. Goddard, C. Ollivier, L. Fensterbank, Angew. Chem. Int. Ed. 2015, 54, 11414-11418. c) J.-I. Yoshida, K. Tamao, T. Kakui, A. Kurita, M. Murata, K. Yamada, M. Kumada, Organometallics 1982, 1, 369-380.

[14] a) J. E. Boggs, P. Chunyang, V. A. Pestunovich, V. F. Sidorkin, J. Mol. Struct. (THEOCHEM) 1995, 357, 67-73; b) G. I. Csonka, P. Hencsei, J. Comput. Chem. 1996, 17, 767-780; c) V. F. Sidorkin, E. F. Belogolova, M. S. Gordon, M. I. Lazarevich, N. F. Lazareva, Organometallics 2007, 26, 4568-4574; d) V. F. Sidorkin, E. P. Doronina, Organometallics 2009, 28, 5305-5315.

[15] D. Young, Computational Chemistry: A Practical Guide for Applying Techniques to Real World Problems, John Wiley \& Sons, Ltd, New York, 2001, p. 228. 
[16] For the first time the bond stretch isomerism was described during the cleavage of the central covalent $\mathrm{C}-\mathrm{C}$ bond in [2.2.2]-propellanes more than 40 years ago (for review, see e.g.: a) M.-M. Rohmer, M. Benard, Chem. Soc. Rev., 2001, 30, 340-354). Bond stretch isomerism is normally characterized by a two-minima PES when first minimum corresponds to the structure with the bond and the second to the one without it. Note that bond stretch isomerism was observed not only during the cleavage of the covalent but also of the dative bonds Si-P in cage silaphosphanes $\mathrm{XSi}\left(\mathrm{YCH}_{2} \mathrm{CH}_{2}\right)_{3} \mathrm{P}$ (ref. 14d) and $\mathrm{P}-\mathrm{N}$ in phosphatranes $\left.\mathrm{X}=\mathrm{P}\left(\mathrm{NRCH}_{2} \mathrm{CH}_{2}\right)_{3} \mathrm{~N}\right)$ ( b) T. Kárpáti, T. Veszprémi, N. Thirupathi, X. Liu, Z. Wang, A. Ellern, L. Nyulászi, J. G. Verkade, J. Am. Chem. Soc. 2006, 128, 1500-1512).

[17] a) M. Dakkouri, M. Grosser, J. Mol. Struct. 2001, 559, 7-24; b) S. L. Hinchley, H. E. Robertson, D. W. H. Rankin, W.-W. du Mont, J. Chem. Soc. Dalton Trans. 2002, 37873794; c) U. Losehand, N. W. Mitzel, D. W. H. Rankin, J. Chem. Soc. Dalton Trans. 1999, 4291-4297.

[18] For RCs of silatranes with the aromatic substituents the MP2 geometry optimization did not converge with the 6-311G(2d,p) basis set.

[19] V. Jouikov, Rus. Chem. Rev. 1997, 66, 509-540.

[20] H. B. Schlegel, J. Phys. Chem. 1988, 92, 3075-3078.

[21] a) A. B. Trofimov, V. G. Zakrzewski, O. Dolgounitcheva, J. V. Ortiz, V. F. Sidorkin, E. F. Belogolova, M. Belogolov, V. A. Pestunovich, J. Am. Chem. Soc. 2005, 127, 986-995; b) V. F. Sidorkin, E. F. Belogolova, E. P. Doronina, Phys. Chem. Chem. Phys. 2015, 17, 2622526237.

[22] a) A. Bard, L.R. Faulkner, in Electrochemical Methods. Fundamentals and applications, New York: John Wiley \& Sons, 2001, pp. 19-24; b) C. P. Andrieux, J.-M. Savéant, in Investigations of Rates and Mechanisms of Reactions, Vol. 6, 4/E, Part 2, Chap. 7 (Ed.: C. F. Bernasconi), Wiley, New York, 1986, pp. 305-390; c) O. Hammerich, in Organic Electrochemistry, 4th ed (Eds.: O. Hammerich, H. Lund), CRC Press, 2000, pp. 95-182.

[23] J. O. Howell, J. M. Goncalves, C. Amatore, L. Klasinc, R. M. Wightman, J. K. Kochi, J. Am. Chem. Soc. 1984, 106, 3968-3976.

[24] V. V. Pavlishchuk, A. W. Addison, Inorg. Chim. Acta, 2000, 298, 97-102.

[25] C. K. Mann, K. K. Barnes, Electrochemical Reactions in Nonaqueous Systems, Marcel Dekker Inc, NY, 1970, p. 560.

[26] V. Jouikov, M. Postnikova, Electrochim. Acta 1995, 40, 803-807.

[27] P. Malachesky, Anal. Chem. 1969, 41, 1493-1494.

[28] J. J. Guerard, J. S. Arey, J. Chem. Theory Comput. 2013, 9, 5046-5058.

[29] M. Namazian, M. L. Coote, J. Phys. Chem. A, 2007, 111, 7227-7232. 
[30] R. S. Mulliken, J. Chem. Phys. 1955, 23, 1833-1840.

[31] K. B. Wiberg, Tetrahedron 1968, 24, 1083-1096.

[32] A. R. Cherkasov, V. I. Galkin, R. A. Cherkasov, Rus. Chem. Rev. 1996, 65, 695-711.

[33] P. Zuman, Substituent Effects in Organic Polarography, NY, Plenum Press, 1967, p. 384.

[34] P. Hencsei, Struct. Chem. 1991, 2, 21-26.

[35] M. G. Voronkov, A. N. Egorochkin, O. N. Kuznetsova, J. Organomet. Chem. 2006, 691, $159-164$.

[36] J. H. Iwamiya, G. E. Maciel, J. Am. Chem. Soc. 1993, 115, 6835-6842.

[37] L. K. Sviatenko, L. Gorb, F. C. Hill, J. Leszczynski, J. Comput. Chem. 2013, 34, 10941100.

[38] J. E. Bartmess, J. Phys. Chem. 1994, 98, 6420-6424.

[39] a) J. P. Perdew, in Electronic Structure of Solids '91 (Eds.: P. Ziesche, H. Eschrig), Akademie Verlag, Berlin, 1991, pp. 11-20; b) A. D. Becke, J. Chem. Phys. 1993, 98, $5648-5652$.

[40] a) V. Barone, M. Cossi, J. Phys. Chem. A 1998, 102, 1995-2001; b) M. Cossi, N. Rega, G. Scalmani, V. Barone, J. Comput. Chem. 2003, 24, 669-681.

[41] A. Klamt, G. Schüürmann, J. Chem. Soc., Perkin Trans. 1993, 2, 799-805.

[42] G. Scalmani, M. J. Frisch, J. Chem. Phys. 2010, 132, 114110-114124.

[43] a) C. P. Kelly, C. J. Cramer, D. G. Truhlar, J. Chem. Theory Comput. 2005, 1, 1133-1152;

b) A. V. Marenich, R. M. Olson, C. P. Kelly, C. J. Cramer, D. G. Truhlar, J. Chem. Theory Comput. 2007, 3, 2011-2033; c) A. V. Marenich, C. J. Cramer, D. G. Truhlar, J. Phys. Chem. B 2009, 113, 6378-6396.

[44] H. B. Schlegel, J. Phys. Chem. 1988, 92, 3075-3078.

[45] B. N. Plakhutin, in Reviews of Modern Quantum Chemistry, Vol. 1 (Ed.: K. D. Sen), Word Scientific, New Jersey, 2002, pp. 16-42.

[46] W. von Niessen, J. Schirmer, L. S. Cederbaum, Comput. Phys. Rep. 1984, 1, 57-125.

[47] F. Neese, ORCA Version 3.0.0, Max-Planck-Insitut für Bioanorganische Chemie, Mülheim and der Ruhr, 2013 (http://www.thch.uni-bonn.de/tc/orca/).

[48] M. W. Schmidt, K. K. Baldridge, J. A. Boatz, S. T. Elbert, M. S. Gordon, J. H. Jensen, S. Koseki, N. Matsunaga, K. A. Nguyen, S. Su, T. L. Windus, M. Dupuis, J. A. Montgomery, J. Comput. Chem. 1993, 14, 1347-1363.

[49] A. A. Granovsky, Firefly version 8, www http://classic.chem.msu.su/gran/firefly/index.html.

[50] A. E. Reed, L. A. Curtiss, F. Weinhold, Chem. Rev., 1988, 88, 899-926. 
[51] E. D. Glendening, J. K. Badenhoop, A. E. Reed, J. E. Carpenter, J. A. Bohmann, C. M. Morales and F. Weinhold, NBO 5.G, Theoretical Chemistry Institute, University of Wisconsin, Madison, WI, 2004, http://www.chem.wisc.edu/ nbo5.

[52] M. J. Frisch, G. W. Trucks, H. B. Schlegel, G. E. Scuseria, M. A. Robb, J. R. Cheeseman, G. Scalmani, V. Barone, B. Mennucci, G. A. Petersson, H. Nakatsuji, M. Caricato, X. Li, H. P. Hratchian, A. F. Izmaylov, J. Bloino, G. Zheng, J. L. Sonnenberg, M. Hada, M. Ehara, K. Toyota, R. Fukuda, J. Hasegawa, M. Ishida, T. Nakajima, Y. Honda, O. Kitao, H. Nakai, T. Vreven, J. A. Montgomery, Jr., J. E. Peralta, F. Ogliaro, M. Bearpark, J. J. Heyd, E. Brothers, K. N. Kudin, V. N. Staroverov, T. Keith, R. Kobayashi, J. Normand, K. Raghavachari, A. Rendell, J. C. Burant, S. S. Iyengar, J. Tomasi, M. Cossi, N. Rega, J. M. Millam, M. Klene, J. E. Knox, J. B. Cross, V. Bakken, C. Adamo, J. Jaramillo, R. Gomperts, R. E. Stratmann, O. Yazyev, A. J. Austin, R. Cammi, C. Pomelli, J. W. Ochterski, R. L. Martin, K. Morokuma, V. G. Zakrzewski, G. A. Voth, P. Salvador, J. J. Dannenberg, S. Dapprich, A. D. Daniels, O. Farkas, J. B. Foresman, J. V. Ortiz, J. Cioslowski and D. J. Fox, Gaussian 09, Revision C.01, Gaussian Inc., Wallingford, CT, 2010.

[53] R. F. W. Bader, Atoms in Molecules: a Quantum Theory, Clarendon Press, Oxford, 1990, p. 458.

[54] E. Espinosa, E. Molins, J. Chem. Phys. 2000, 113, 5686-5694.

[55] a) A. A. Korlyukov, Russ. Chem. Rev. 2015, 84, 422-440; b) K. A. Lyssenko, A. A. Korlyukov, D. G. Golovanov, S. Yu. Ketkov, M. Yu. Antipin, J. Phys. Chem. A 2006, 110, 6545-6551; c) E. A. Zhurova, A. I. Stash, V. G. Tsirelson, V. V. Zhurov, E. V. Bartashevich, V. A. Potemkin, A. A. Pinkerton, J. Am. Chem. Soc. 2006, 128, 1472814734; d) V. F. Sidorkin, E. P. Doronina, E. F. Belogolova, Chem. Eur. J. 2013, 19, 1030210311.

[56] a) P. L. A. Popelier, Comput. Phys. Commun. 1996, 93, 212-240; b) P. L. A. Popelier, Chem. Phys. Lett. 1994, 228, 160-164.

[57] G. A. Zhurko, D. A. Zhurko, Chemcraft, Version 1.7 (build 382) (http://www.chemcraftprog.com)

[58] K. Tamao, T. Hayashi, Y. Ito, M. Shiro, Organometallics 1992, 11, 2099-2114.

[59] Irkutsk Supercomputer Center of SB RAS, Irkutsk: ISDCT SB RAS (http://hpc.icc.ru), accessed August 2016. 